\title{
Fractionating the Word Repetition Effect with Event-Related Potentials
}

\author{
Cyma Van Petten \\ Department of Psychology \\ University of Arizona \\ and Department of Cognitive Science \\ University of California, San Diego
}

Marta Kutas, Robert Kluender, Mark Mitchiner, and Heather McIsaac

Department of Cognitive Science

University of California, San Diego

\begin{abstract}
Word repetition has been a staple paradigm for both psycholinguistic and memory research; several possible loci for changes in behavioral performance have been proposed. These proposals are discussed in light of the event-related brain potential (ERP) data reported here. ERPs were recorded as subjects read nonfiction articles drawn from a popular magazine. The effects of word repetition were examined in this relatively natural context wherein words were repeated as a consequence of normal discourse structure. Three distinct components of
\end{abstract}

\section{INTRODUCTION}

Word repetition is a seemingly simple experimental phenomenon: subjects are faster and more accurate in their responses to words on second presentation than on first presentation. This result has been obtained across a range of tasks including pronunciation, tachistoscopic identification, word stem completion, lexical decision, semantic categorization, syntactic categorization, and reading of inverted text (Jacoby, 1983; Feustel, Shiffrin, \& Salasoo, 1983; Kolers, 1973, 1976; Monsell, 1985; Scarborough, Cortese, \& Scarborough, 1977; Warrington \& Weiskrantz, 1974). Word repetition is also a complex phenomenon that has generated an enormous experimental literature because it lies at the interface between research domains concerned primarily with language processing, where repetition effects might be expected to bear on some basic questions about lexical representation, and those concerned primarily with learning and memory, where words serve as convenient stimuli to test various theories of encoding and retrieval in humans. the ERP were found to be sensitive to repetition: a positive component peaking at $200 \mathrm{msec}$ poststimulus, a negative one at $400 \mathrm{msec}(\mathrm{N} 400)$, and a later positivity. The components were differentially sensitive to the temporal lag between repetitions, the number of repetitions, and the normative frequency of the eliciting word. The $\mathrm{N} 400$ responded similarly to repetition in text as it has in experimental lists of words, but the late positivity showed a different pattern of results than in list studies.

\section{Lexical versus Episodic Accounts of Word Repetition Effects}

Two distinct views of word repetition effects have emerged that assume different underlying knowledge structures for an individual's vocabulary. Within logogentype models, lexical knowledge is distinct from other sorts of knowledge, and lexical representations are relatively fixed. In this class of models, repetition priming is presumed to reflect a change of activation or threshold level of a word unit due to the recent occurrence of that word. This change is ahistoric, carrying with it no additional information about when or where the word was encountered. These repetition-induced changes of state decay over time, but gradually, so that the logogens for more commonly encountered words remain in a more active state than those for less common words. Experimental effects due to normative frequency of a word's occurrence within one's language, and those due to repetition during an experiment are thus ascribed to a common mechanism (Morton, 1969). In contrast, episodic 
accounts of word repetition effects stress the retrieval of memories for particular encounters with a given word. In this framework, performance on the current word will benefit to the extent that past encounters were (1) perceptually or semantically similar, (2) included contexts that overlap with the present context, and (3) demanded similar operations to perform the experimental task (Jacoby, 1983; Jacoby \& Dallas, 1981).

Finally, there is the possibility that two distinct memory systems subserve word repetition effects. Amnesic patients show repetition priming effects on some tasks in the absence of conscious recollection for the first presentation of a word (Tulving, Schacter, \& Stark, 1982; Schacter, 1987). This three- way debate is far from resolved and, as noted above, there are a large number of studies of word repetition effects lending support to each view. We will not review this literature in any detail here since a number of excellent reviews and discussions exist (Carr, Brown, \& Charalambous, 1989; Forster, 1985; Jacoby \& Dallas, 1981; Monsell, 1985, 1991; Roediger, Weldon, \& Challis, 1989; Schacter, 1987). We will, however, argue that recordings of event-related brain potentials (ERPs) provide a useful source of data converging with those from other techniques, and that ERP data do indeed suggest multiple sources of repetition effects.

\section{Event-Related Brain Potentials as a Measure of Cognitive Operations}

As a response measure, the ERP is more complex than a simple scalar measure such as reaction time or error rate. Via stimulus and task manipulations, different segments or components of the ERP can be attributed to distinct functional processes (see Hillyard \& Kutas, 1983; Hillyard \& Picton, 1987 for reviews). The multicomponent nature of the response thus allows for qualitative, as well as quantitative, comparisons of the impact of different experimental manipulations in that a particular manipulation may influence one component but not another in the ERP elicited by the same stimulus.

Although the scalp-recorded ERP is indirect as a neurophysiological measure, its noninvasive nature places it as a "bridge" between performance measures and more direct records of neural activity. To the extent that information about the generators of various components can initially be gleaned through the concurrent use of other techniques, ERPs can subsequently be applied within a broader range of situations to assess the contributions of different brain regions to cognitive operations. A similar research strategy has been applied to the early "noncognitive" components of the ERP with enough success that abnormalities in these components now aid clinicians to pinpoint the source and nature of neurological disorders (see Chiappa, 1983; Cracco \& Bodis-Wollner, 1986). For the late, "cognitive" components of the ERP, a range of techniques are being used for the purpose of localization, including lesion studies in animals, concurrent sin- gle or multiple unit recordings in animals, field potentials recorded within or at the surface of the human cortex, recordings from humans after surgical ablations, and measures of regional glucose utilization (Arezzo, Vaughan, Kraut, Steinschneider, \& Legatt, 1986; Halgren, 1990; Kutas, Hillyard, \& Gazzaniga, 1988; McCarthy \& Wood, 1984; Pineda, Foote, \& Neville, 1989; Smith \& Halgren, 1989; Smith, Stapleton, \& Halgren, 1986).

\section{Word Processing and the N400 Component}

At the functional level of analysis, the ERP component that has been most closely tied to word processing is the N400 (Kutas \& Van Petten, 1988; Van Petten \& Kutas, 1991b). This component was first noted in experiments using sentence stimuli that ended congruently and predictably (e.g., "The pizza was too hot to eat.") while others were terminated by a semantically incongruent word (e.g., "He shaved off his mustache and city."). Predictable words elicited a late positive wave while incongruent endings elicited a negative wave beginning about $200 \mathrm{msec}$ post stimulus and peaking at $400 \mathrm{msec}$; the difference between these two ERPs resolved at about 600 msec poststimulus (Kutas \& Hillyard, 1980a,b,c). Since these original experiments, it has been shown that finer gradations of semantic context also will modulate the amplitude of the N400. First, N400 amplitude shows a strong inverse correlation with the predictability of the eliciting word within a particular sentence context (Kutas \& Hillyard, 1984; Kutas, Lindamood, \& Hillyard, 1984) Second, the size of the N400 elicited by sentence-intermediate words declines across the course of a sentence, becoming smaller with each additional open-class word (Van Petten \& Kutas, 1990). This latter effect reflects the buildup of contextual constraints as a sentence proceeds; the linear decrement does not occur in random word strings (Van Petten \& Kutas, 1991a).

\section{ERP Word Repetition Effects}

A number of studies have examined the effects of repetition on the ERPs elicited by words in lists. Rugg (1985) initially compared the effects of repetition to those of associative semantic priming. He found that both repeated and semantically primed words elicited more positive ERPs than did new or unrelated words in the latency range of 300 to $500 \mathrm{msec}$ post stimulus. The two priming effects had the same scalp distribution, consistent with the conclusion that both repeated and related words elicit a smaller $\mathrm{N} 400$ in lists. However, the repetition effect was more prolonged than the semantic priming effect, persisting until some $700 \mathrm{msec}$ poststimulus. Subjects in this experiment (Rugg, 1985) performed a lexical decision task; the repeated words followed either immediately after the initial presentation of the same word, or with a lag of one intervening letter string (word or nonword). Subsequent experiments have evaluated 
the impact of task and repetition lag. With a few important exceptions described below, these have produced remarkably replicable results in that the ERP to repeated words is more positive than that to unrepeated words beginning 250-300 msec and extending as late as 800 msec poststimulus (Bentin \& Peled, 1990; Karayanidis, Andrews, Ward, \& McConaghy, 1991; Nagy \& Rugg, 1989; Rugg, 1987, 1990; Rugg, Furda, \& Lorist, 1988; Rugg \& Nagy, 1987, 1989; Smith \& Halgren, 1989). This result has held over repetition lags from 0 to 19 (or approximately 3 to $75 \mathrm{sec}$ across the various experiments), and for tasks including explicit lexical decision, maintaining a silent count of either words or nonwords (implicit lexical decision), classification of words as repeated or unrepeated, or a semantic classification task of responding to occasional animal names. The studies cited above were all conducted in the visual modality, but a similar result has been reported for the repetition of spoken words, and for crossmodal repetition (Feldstein, Smith, \& Halgren, 1987).

Given that prior presentation of a semantically related word will suppress the amplitude of the N400 (Bentin, McCarthy, \& Wood, 1985; Holcomb, 1988; Kutas \& Hillyard, 1989; McCallum, Farmer, \& Pocock, 1984), it is hardly surprising that prior presentation of the same word will also reduce its amplitude. The long duration of the ERP repetition effect is, however, somewhat puzzling. In the most simple-minded analysis, we might consider identity priming to be the sum of two factors: an extreme case of semantic priming, and a short-term updating of the frequency of usage for the repeated word. However, associative priming effects in both word pairs and sentences are less prolonged than the repetition effect (Kutas \& Hillyard, 1989; Van Petten, 1989). Similarly, commonly used words elicit smaller N400s than low frequency words in some cases, but these effects on N400 amplitude in both lists and sentences are brief, lasting only some $200 \mathrm{msec}$ as compared to the 500 or $600 \mathrm{msec}$ of the repetition effect (see top row of Figure 1; also Smith \& Halgren, 1987; Van Petten \& Kutas, 1990, 1991a). Thus, neither associative priming nor word frequency effects are individually of long enough duration to account for the repetition effect, and since they occur in much the same latency range, it is unlikely that their summation would yield a long duration effect either. Finally, in most of the ERP repetition studies cited above, the repetition effect extends well beyond the apparent peak of the N400. These considerations suggest that the repetition effect observed in these word-list experiments may consist of the modulation of more than one ERP component, for example, that repeated words elicit a larger late positive wave as well as a smaller N400.

Two recent studies have demonstrated partial dissociations between the $\mathrm{N} 400$ and late positive consequences of repetition. The first of these distinguished between the two effects on the basis of their different distributions across the scalp. ${ }^{1}$ In the only ERP sentencerepetition experiments to date, Besson and colleagues repeated a block of 160 sentences either once or twice in separate experiments (Besson, Kutas, \& Van Petten, 1986, in press, submitted). The ERPs to sentence final words showed a repetition effect that was even longer than that observed in word lists, consisting of a greater positivity for repetitions that extended from 300 to 1300 msec poststimulus. Half of the sentences in these experiments ended incongruously, a manipulation which allowed a direct comparison between the repetition effect and the N400 sentence-incongruity effect. In the N400 latency range, both effects showed the typical scalp distribution of the N400: larger over posterior than anterior recording sites, and slightly larger over the right than the left hemisphere (see also Kutas \& Hillyard, 1982; Kutas, Van Petten, \& Besson, 1988). In contrast, the later phase of the repetition effect (600-1300 msec poststimulus) was equipotential across the scalp, showing neither a bilateral nor an anterior-posterior gradient. Besson's distributional analyses thus indicate that the N400 is sensitive to both semantic congruity and repetition, but that an additional, somewhat later component of the ERP is also modulated by repetition.

Rugg (1990) has similarly argued that there are at least two components to the ERP repetition effect based on differences between high-and low-frequency words in a word-list experiment. We will describe this experiment in some detail because it offers the clearest evidence to date for the involvement of two components, and because Rugg has offered an account of the significance of the two components in terms of current cognitive theory. In Rugg's experiment, subjects responded to occasional nonwords mixed with new and repeated words of high and low frequencies of usage [greater than 100, and less than 1 occurrence per million in the Kučera and Francis (1967) count]. In Phase 1 of the experiment, half of the words were repeated with a lag of 6 intervening items, and half were presented only once. Phase 2 followed 15 min later; in this portion of the experiment, words that had occurred only once during Phase 1 were presented for the second time, intermixed with new words. New low-frequency words elicited larger N400s than new high-frequency words, but with short repetition lag (Phase 1) this frequency effect disappeared. This finding is in accord with the results of Smith and Halgren (1987) who also observed a frequency by repetition interaction in a word-list experiment, and with those of Besson et al. (submitted) who observed an attenuation of the N400 frequency effect for sentence-intermediate open class words when the sentences were repeated.

Two additional findings of this experiment are of greater import for our present goal of fractionating the ERP repetition effect. First, with a repetition lag of 15 min (Phase 2), there was little sign of a reduction in N400 amplitude, but repeated words did elicit an en hanced late positivity beginning some $500 \mathrm{msec}$ poststimulus. This finding corroborates two previous reports that decreases of N400 amplitude are not observed with 


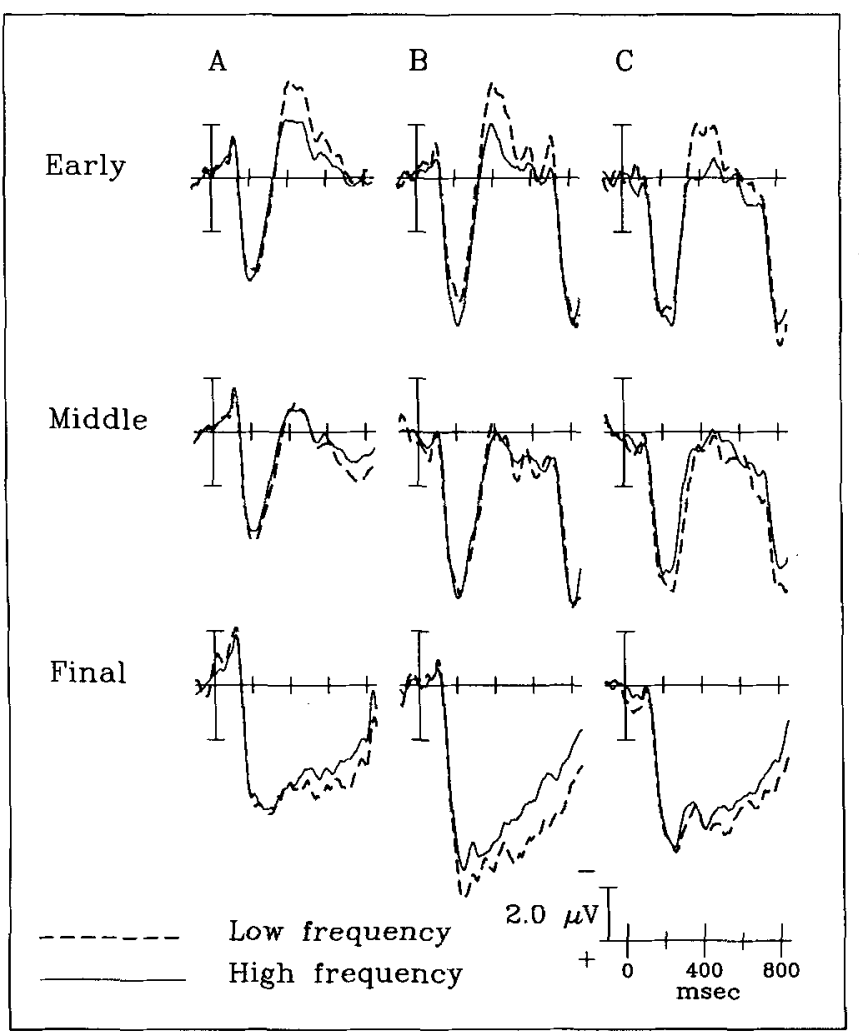

Figure 1. The influence of word frequency is shown for three previous experiments using independent sentences rather than connected discourse as in the present study (column A data from Van Petten \& Kutas, 1990; B from Van Petten \& Kutas, 1991a; C from Van Petten, 1989). "Low" and "high" frequency refer to less or greater than 30 occurrences per million in the Francis and Kucera (1982) count. In each experiment, low-frequency words elicited larger N400s when they appeared as the first open class word of a sentence ("early," typically the second or third word of a sentence). In midsentence positions, high- and low-frequency words elicit equivalent ERPs. In late or sentence-final positions, low frequency words elicit more positive ERPs.

very long repetition lags in word lists, while increases in a late positive component (LPC) are (Fischler, Boaz, McGovern, \& Ransdell, 1987; Rugg \& Nagy, 1989). Second, at both lags, repeated low-frequency words elicited a larger late positivity than repeated high-frequency words or either type of new word. The LPC portion of the repetition effect thus (1) persisted over longer lags than the N400 effect, and (2) was specific to low-frequency words. $^{2}$

In Rugg's theoretical account of the N400 and LPC, these two repetition-sensitive ERP components index distinct and unrelated cognitive processes. On the one hand, the N400 "reflects a post-lexical process that is invoked in proportion to the degree that the evoking stimulus and its context form an unfamiliar or unexpected conjunction. Within this framework, the present results suggest that high frequency words form a less unfamiliar conjunction with the experimental context than do low frequency items, presumably because of their more fre- quent past exposures in a wider range of contexts" (1990, pp. 375-376). We believe there are problems inherent in this and similar definitions of the process generating the N400. These are discussed elsewhere (Van Petten, 1989; Van Petten \& Kutas, 1991b) and only the most salient points are repeated here. We have some general difficulties with the terms "prelexical" and "postlexical" as descriptions of time intervals during the processing of a word because they relegate "lexical" to a single intervening time point rather than an extended period of word encoding and comprehension (see also Balota, 1990 for a discussion of the "magic moment" in word processing). In any case, "postlexical" processing can be relevant only if the stimulus under consideration is a word. However, nonwords elicit large N400s if they are orthographically legal and some processing is required to determine that they are not, in fact, words (Bentin, 1987; Bentin, McCarthy \& Wood, 1985; Holcomb, 1988; Rugg \& Nagy, 1987; Smith \& Halgren, 1987). Futhermore, we find the "unfamiliar conjunction" account of the N400 frequency effect to be unrevealing. Low-frequency words elicit larger N400s than high-frequency words when these occur as the second words of sentences beginning with articles or pronouns (Kutas et al., 1988; Van Petten \& Kutas, 1990, 1991a). To say that a phrase such as "The trash" (with a frequency of $2 /$ million) forms a less familiar conjunction than "The cbild" (with a frequency of $620 /$ million) is simply to restate the fact that low-frequency words are less common than high-frequency words.

In his account of the LPC repetition effect and its specificity to low-frequency words, Rugg invokes the concept of "relative perceptual fluency" originally developed to help explain the typical advantage of low- over highfrequency words in tests of recognition memory (Jacoby, 1983; Jacoby \& Dallas, 1981; Mandler, 1980). Low-frequency words have low baseline familiarity because of their rarity in the language, but prior occurrence in an experimental list provides such words with a high local familiarity on repetition. Rugg (1990) postulates that it is this discrepancy between baseline and local familiarity that elicits the enhanced late positivity for low-frequency words on repetition.

Rugg's exposition of the LPC repetition effect accounts nicely for the data reported in his 1990 study. However, note that this is a more general account lending support to a particular cognitive model of memory, and further identifying a particular ERP component with a hypothetical memory process (the calculation of "relative fluency"). We believe that any single experiment is too limited a base for so definitive a conclusion.

The particular limitations of Rugg's study allow several alternative interpretations of the LPC repetition effect for low-frequency words. First, the subjects were performing a lexical decision task (respond only to nonwords) with rare words, some of which may have been only marginally within their working vocabularies. If a subject had 
some doubt as to an item's lexical status on first presentation, the lexical decision on second presentation may have become easier simply from practice. Moreover, since nonwords were never repeated, any item appearing for a second time could clearly be tagged as a word. Consistent with one or both of these possibilities is the fact that subjects' error rates for low-frequency words (i.e., a nonword response) were higher than those for high-frequency words, and decreased with repetition. The potential impact of these possibilities on the subjects' ERPS is that high-confidence decisions have generally been associated with larger P300s (a type of late positivity) than low-confidence decisions in signal detection tasks (Paul \& Sutton, 1972; Squires, Hillyard, Lindsay, 1973b; Squires, Squires \& Hillyard, 1975). An interpretation of the LPC repetition effect as a reflection of subjects' confidence in their decisions would still identify the enhanced LPC as a repetition effect, but would restrict its generality to situations that require dichotomous decisions.

The extensive literature on the sensitivity of the P300 to decision-related processes raises another possible problem in interpreting the repetition data from Phase 1 of Rugg's experiment. Words were repeated with a fixed lag of six intervening items. One might suspect that subjects would become aware of this contingency after some time in the experiment, and perhaps begin to predict the occurrence and the identity of repeated items. Feedback about a prediction has also been shown to yield P300s (Horst, Johnson, \& Donchin, 1980; Squires, Hillyard, \& Lindsay, 1973a). However, this potential confound is somewhat lessened by the fact that the repeated items in Phase 2 of the Rugg study occurred on a less predictable schedule.

Rugg's interpretation of the LPC repetition effect as an index of "relative perceptual fluency" inherits a problem that is endemic to ERP research, namely the difficulty in separating temporally overlapping components. The LPC was assumed to increase with repetition, but this may have appeared to be the case only because an overlapping negative component, the $\mathrm{N} 400$, became smaller with repetition. In other words, the LPC may be an effect of frequency per se, which is visible only when the standing $\mathrm{N} 400$ difference between high- and low-frequency words is eliminated by repetition.

Finally, we should note that we have some empirical reasons to suspect that the larger LPC for low- than highfrequency words is not a specific response to repetition. In several experiments examining the combined effects of word frequency and sentence context, we have consistently observed that low-frequency words elicit larger $\mathrm{N} 400$ s than high-frequency words in the early portion of meaningful sentences (and throughout nonsensical sentences) but equivalent ERPs in mid-sentence positions. However, at or near the ends of sentences, low-frequency words elicit more positive ERPs than high-frequency words. This pattern of results is shown in Figure 1 for three experiments. Previously, we did not attribute great significance to this apparent late positive frequency effect because high- and low-frequency words were not matched for length in all cases, nor was the late positive difference statistically significant in all experiments (Van Petten \& Kutas, 1991a; Van Petten, 1989). However, the similarity between this late positivity and the late positivity elicited by repeated low frequency words warrants further consideration. At bare minimum, a functional classification of ERP memory/repetition/word processing effects will require that we understand the set of circumstances under which low-frequency words elicit larger late positivities than high-frequency words.

\section{The Present Experiment}

The present study adds to our knowledge about the generality and nature of repetition effects through the use of an experimental paradigm that is quite different from both the word list and sentence repetition studies conducted to date. We recorded ERPs as subjects read short texts for comprehension, and compared the resprnses to new versus repeated words. Stimuli were presented one word at a time on a CRT monitor at a variable rate (320-680 msec interword interval, see Methods). A multiple choice comprehension test was administered at the end of each text. This paradigm is naturalistic and observational in that we did not edit the texts to introduce repetitions nor did we ask subjects to note repetitions. Rather, we recorded the consequences of repetition as a function of (1) the normative frequency of the word's occurrence in written English, (2) the lag since the most recent occurrence of the word, (3) the number of repetitions of the word, and (4) whether the word was a proper name or not.

Using textual stimuli clearly introduces sources of variance that are more easily controlled with simpler stimulus materials. For instance, the importance or information load of each word in a passage will vary, as will its syntactic role. However, given the large number of reports of repetition effects in lists, we think the benefits of a new paradigm for examining the generality of these effects outweigh the complications. One advantage of the text paradigm is its freedom from experimentally induced decision factors known to influence the amplitude of the P300. A second advantage is that we expect the semantic context provided by the text to eliminate the N400 difference between high- and low-frequency words. In the absence of the N400 frequency effect, it will be easier to ascertain the relationships between the late positive component, word frequency, and repetition.

\section{RESULTS}

\section{Effects of Frequency and Repetition}

All words elicited a series of voltage deflections familiar from previous experiments using words as stimuli: a P1 
at temporal and occipital sites peaking at about $130 \mathrm{msec}$, a frontal $\mathrm{N} 1$ peaking at about $110 \mathrm{msec}$, a temporaloccipital N1 peaking at about $180 \mathrm{msec}$, and a $\mathrm{P} 2$ peaking at about $250 \mathrm{msec}$ that was visible at all the recording sites but largest at frontal and central sites. The primary effects of repetition are on the $\mathrm{N} 400$ and a later positivity, both visible at all electrode sites.

Figure 2 shows the ERPs elicited by content words (nouns, verbs, adjectives, and derived adverbs) as a function of normative frequency of occurrence. For words occurring for the first time in the experiment, frequency had little impact on the N400, but new low-frequency words elicited a larger LPC than high-frequency words. The LPC frequency effect began about $500 \mathrm{msec}$ and extended as late as $900 \mathrm{msec}$ poststimulus. Low-frequency words also elicited more positive ERPs when repeated, but here the difference begins somewhat earlier in the epoch, apparent as early as $400 \mathrm{msec}$ poststimulus. $^{3}$

Figure 3 shows the effects of repetition for both highand low-frequency words. For high-frequency words, the predominant effect is a reduction in $\mathrm{N} 400$ amplitude, although a slight decrease in the late positivity is apparent

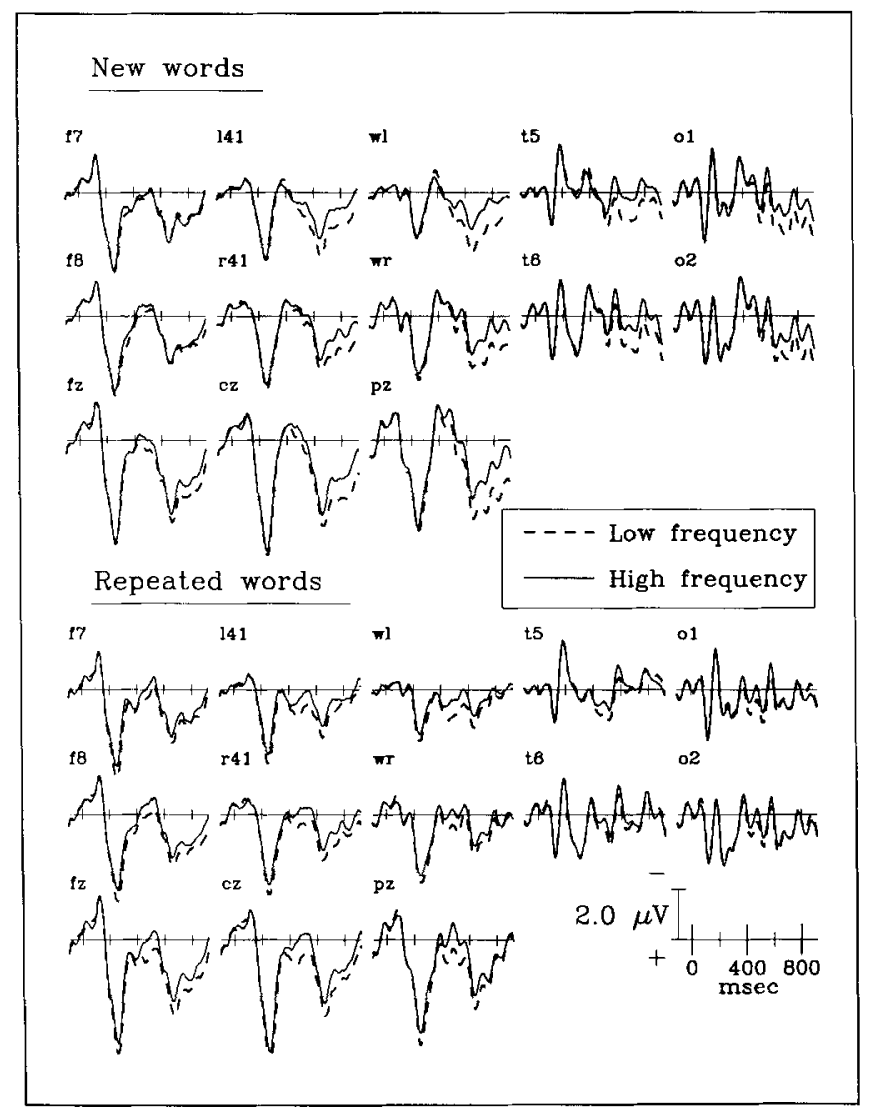

Figure 2. Grand average ERPS across 40 subjects, according to the normative frequency of the eliciting words. Top: new words. Bottom: repeated words. In both sections, ERPs recorded from the left side of the head are shown in the first row, right side in the second row, and midline in the third row.

\section{High frequency words}

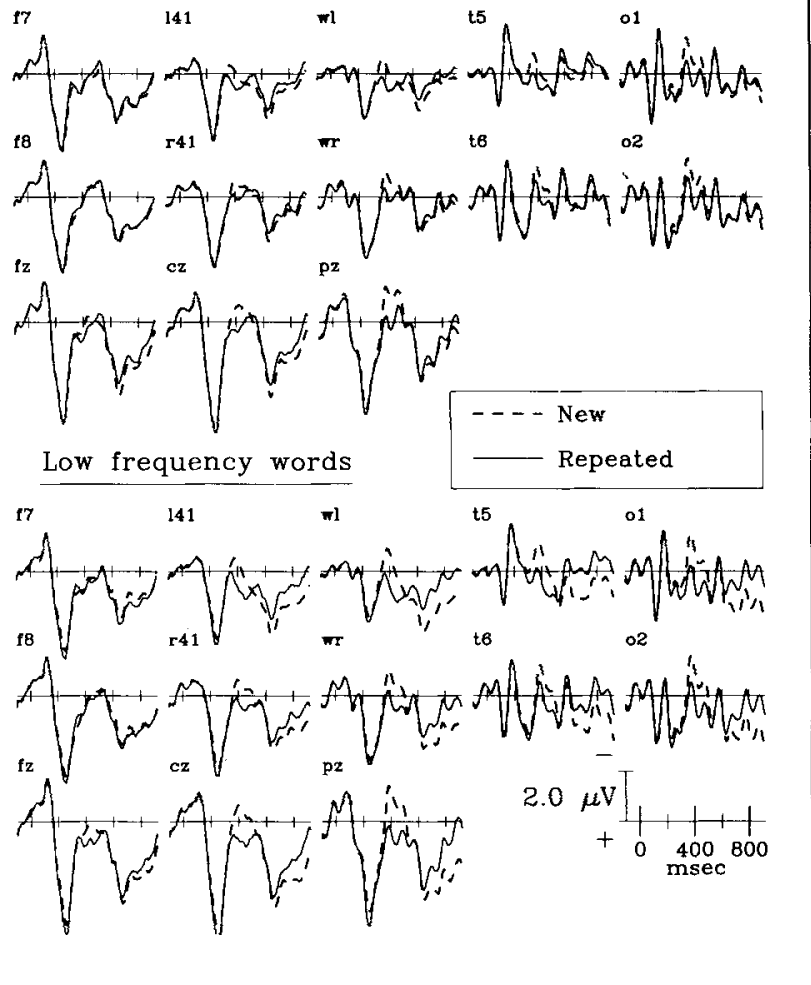

Figure 3. Grand average ERPs across 40 subjects, according to whether the eliciting word was appearing for the first time in its text, or was repeated. Top: high-frequency words. Bottom: low-frequency words.

as well. For low-frequency words, the $\mathrm{N} 400$ was decreased by repetition, and the LPC shows a substantial amplitude reduction.

The multicomponent nature of the repetition effect is clear in Figure 4, which represents the difference waveform formed by subtracting the ERPs elicited by repeated words from those elicited by new words. The N400 phase of the effect is apparent here from 300 to $500 \mathrm{msec}$ poststimulus, followed by the late positive effect. This figure also reveals an earlier effect of repetition. In the region of 180 to $300 \mathrm{msec}$, repeated words elicited a more positive peak than did new words. In the raw waveforms shown in Figure 3, this may have appeared to be the leading edge of the N400 effect. However, the difference wave clearly shows the early peak to have a more anterior scalp distribution than the negativity which follows. This distribution and visual inspection of Figure 3 are consistent with the idea that this early repetition effect is an enhancement of the P2. However, the repetition effect peaks somewhat earlier $(200 \mathrm{msec})$ than the P2 in the raw waveforms ( $250 \mathrm{msec}$ ), so this conclusion cannot be drawn with any certainty. In any case, the early repetition effect was unexpected, but statistically significant in an analysis of variance comparing repeated and 


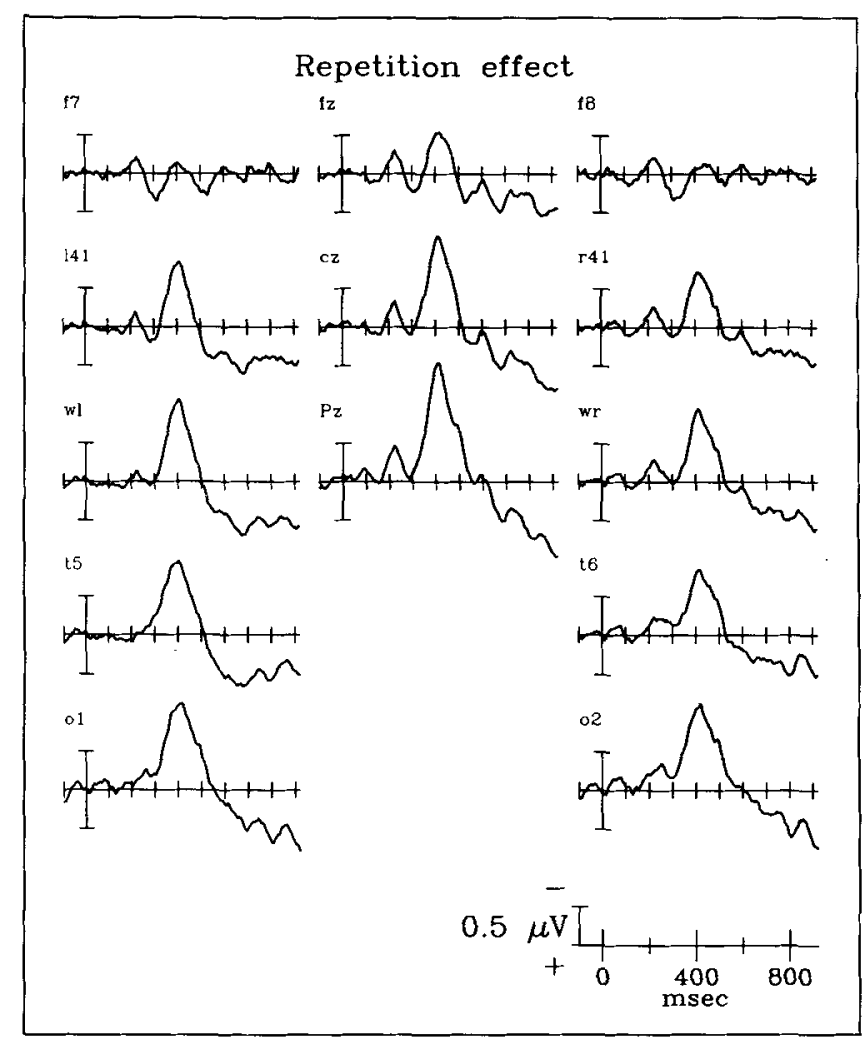

Figure 4. Difference waves formed by subtracting the ERP elicited by all repeated words from that elicited by all new words. Negativity in the difference wave thus indicates that the ERP to new words was more negative than that to repeated words.

unrepeated words at all the recording sites (peak positive amplitude between 180 and 300 msec: $F(1,37)=27.0$, $p<.0001]$. The early effect was larger over right than left hemisphere recording sites [repetition by laterality: $F(1,37)=6.2, p<.05]$. The P2 itself was also larger over the right [main effect of laterality: $F(1,37)=37.7, p<$ $.0001]$ as we have noted in previous experiments (Kutas et al., 1988). The amplitude of this early effect was too small to permit subdividing the repeated and unrepeated words according to any of the other experimental factors without an unacceptable decline in the signal-to-noise ratio.

The remainder of our statistical analyses will thus focus on the N400 and the LPC. We initially selected the latency windows of 300-500 and 500-900 msec poststimulus to quantify the two components. These analyses will be reported first, although we will question whether these latency windows provide a clean separation between the two components and report supplementary analyses to address this issue.

\section{N40O Component}

For the N400 window, mean amplitude measures from each subject at the central, parietal, temporal, and occipital sites were subjected to an analysis of variance using frequency (high or low), repetition (new or repeated), and electrode site (10 levels). This yielded main effects of word frequency $[F(1,37)=4.32, p<.05]$ and repetition $[F(1,37)=72.6, p<.0001)]$. The interaction between frequency and repetition did not reach significance $[F(1,37)=3.46, p=.07]$.

Pairwise comparisons showed that the decrease in N400 amplitude with repetition was significant for both high- $[F(1,37)=50.0, p<.0001]$ and low-frequency words $[F(1,37)=44.5, p<.0001]$. There was no significant frequency effect for new words $[F(1,37)=0.49]$. On repetition, however, the ERPs to low-frequency words were more positive than those to high-frequency words, the reverse of the typical $N 400$ frequency effect $[F(1,37)=9.54, p<.005]$. Together with the marginal $(p=.07)$ interaction from the omnibus ANOVA, these results suggest that repetition had a greater impact on the N400 to low- than to high-frequency words. However, reference to the lower half of Figure 2 will indicate that it is difficult to determine whether the greater positivity for low- than high-frequency repeated words in the N400 latency band should be attributed to a smaller N400 and/ or a larger LPC. We will return to this point below.

$L P C$

Similar analyses were performed on the ERP waveforms in the 500 to 900 latency window. The initial ANOVA yielded main effects of both frequency $[H(1,37)=40.5$, $p<.0001]$ and repetition $[F(1,37)=20.3, p<.0001]$ as well as an interaction between them $[F(1,37)=15.7, p<$ $.0005]$. Pairwise comparisons showed that low-frequency words elicited more positivity than high-frequency words both when they were new $[F(1,37)=44.3, p<.0001]$ and when they were repeated $[F(1,37)=13.6, p<.001]$. Similarly, the reduction in LPC amplitude produced by repetition was significant for both high $[F(1,37)=4.87$, $p<.05]$ and low-frequency words $[F(1,37)=24.3, p<$ $.0001]$. The interaction between frequency and repetition in the omnibus ANOVA thus indicated differences in the degree rather than the direction of the experimental effects: the LPC was initially larger for low-frequency words, and repetition had a larger impact on the LPC elicited by low- than high-frequency words.

\section{Effects of Repetition Lag and Number of Repetitions}

We subdivided the class of repeated words according to the number of intervening words since last occurrence (lag less or greater than 20). Each repeated word was also categorized according to whether it was the first (second occurrence in the text) or additional (third or more occurrence in the text) repetition of that word. These breakdowns are of interest for two reasons. First, given that both the N400 and the LPC were reduced by repetition, an experimental dissociation would improve 
our understanding of the factors driving these two repetition-sensitive components. Second, given that both components are sensitive to normative word frequency, responsiveness to the timing (lag) and number of word occurrences may tell us something about the nature and time course of the learning process that makes some words familiar and others less familiar.

\section{$N 400$}

Mean amplitudes in the 300-500 msec latency window are shown in Figure 5 according to the frequency of the eliciting word (high or low), the lag since last occurrence (short or long), and number of repetitions (first or $2+$ ). A single repetition at a long lag was sufficient to reduce N400 amplitude relative to new words [pairwise comparison: $F(1,37)=18.6, p<.0001]$. However, either short-lag or multiple repetitions drove the amplitude even lower. Repetition lag and number thus showed a tradeoff as determinants of $\mathrm{N} 400$ amplitude. This pattern of results was similar for both high- and low-frequency words. The statistical analysis of the ERPs elicited by repeated words (including the factors of frequency, lag, number, and recording site) thus showed a significant interaction between lag and number $[F(1,37)=9.8, p<$ $.005]$ but no other significant main effects or interactions (except for those involving recording site, which will be described below).

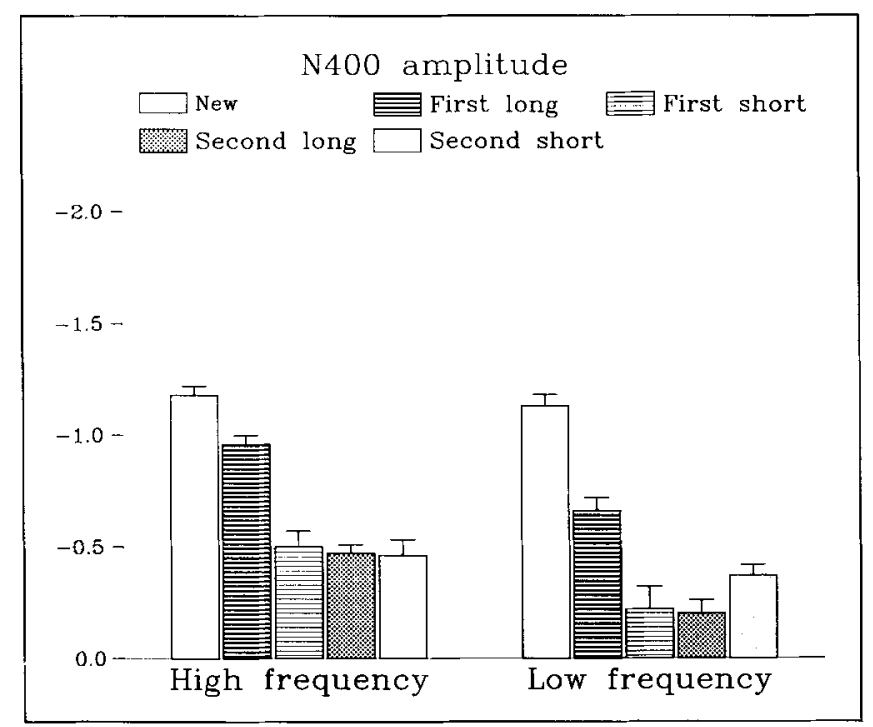

Figure 5. Mean voltage in the N400 latency band of $300-500 \mathrm{msec}$ poststimulus, relative to a $100 \mathrm{msec}$ prestimulus baseline, shown in microvolts with standard error bars. Measures were derived from central, parietal, temporal, and occipital recording sites. New refers to words appearing for the first time in a text, First long to words repeated for the first time with a minimum of 20 words intervening since the initial presentation, First short to first repetitions with a lag of less than 20 words, Second long to second and subsequent repetitions, with at least 20 words intervening since the most recent occurrence, and Second short to second and subsequent repetitions with a short lag.

\section{$L P C$}

Figure 6 shows mean amplitudes in the 500-900 msec latency window, which were subjected to an ANOVA with frequency, lag, number, and recording site as factors. The pattern of results was distinct from that in the $\mathrm{N} 400$ window. First, as evident from Figure 1 and the preceding analyses, the LPC was generally larger for low-frequency words [main effect of frequency: $F(1,37)=23.0, p<$ .0001 ]. Second, the LPC appeared to be generally less sensitive to repetition than the N400. It is primarily for multiple repetitions at short lags that the LPC shows a substantial reduction in amplitude [main effect of number: $F(1,37)=9.53, p<.005$; interaction of lag $\times$ number, $F(1,37)=8.31, p<.01]$. This picture is slightly complicated by the fact that for low-frequency words only, more than a single repetition reduced the LPC, independent of lag [interaction between frequency and number: $F(1,37)=5.05, p<.05$ ]. A post hoc comparison showed that for high-frequency words, there were no significant differences among new words, first repetitions with a short lag, first repetitions with a long lag, and second repetitions with a long $\operatorname{lag}[F(3,111)=1.11]$. Only second repetitions at a short lag differed from new words $[F(1,37)=17.2, p<.0005]$. For low-frequency words, second repetitions at either lag were different from new words [short: $F(1,37)=69.6, p<.0001$; long $F(1,37)=$ $21.5, p<.0005]$, whereas first repetitions at either lag were not [short: $F(1,37)=0.79$; long: $F(1,37)=3.29$ ]. In summary, the LPC responded to multiple repetitions of a word but not to a single repetition. Repetition lag was more critical for high- than low-frequency words in determining LPC amplitude.

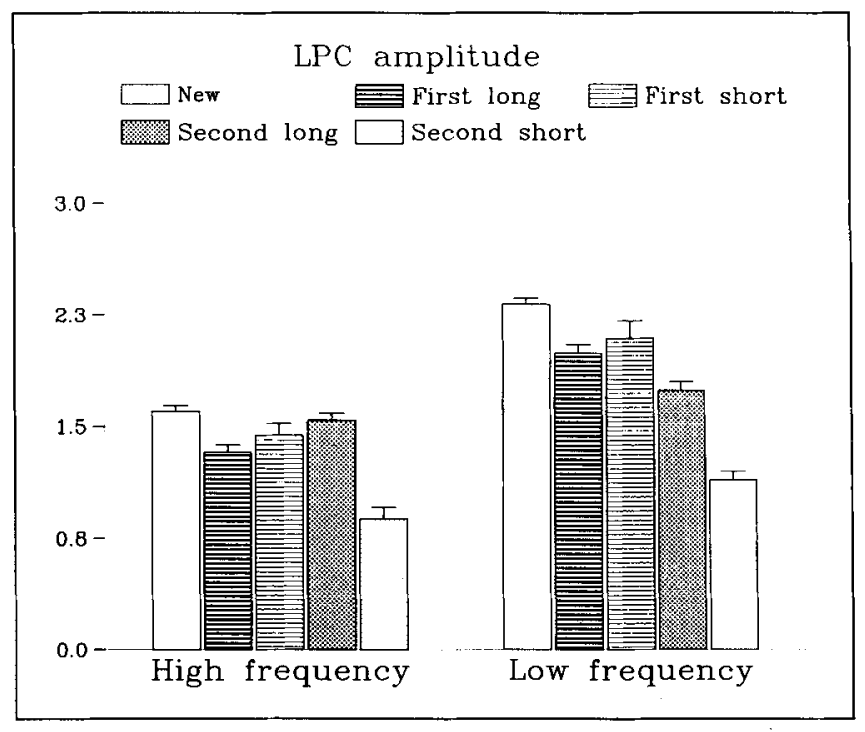

Figure 6. Mean voltage in the latency band of the late positive component, $500-900 \mathrm{msec}$ poststimulus. 


\section{Separability of the Two Components}

In the word list and sentence repetition studies reviewed earlier, it had been difficult to establish the existence of two repetition-sensitive components because a decrease in N400 amplitude and an increase in LPC amplitude combined to yield an increased positivity for repeated words across most of the recording epoch. The present data set provides unequivocal evidence for two repetition-sensitive components simply because they were both reduced by repetition, yielding a biphasic repetition effect rather than a single broad positive effect that could be fractionated only by additional data analyses or experimental manipulations. However, the nature and time course of the effects and their interaction with other variables (such as frequency) are still confounded by the possibility that the two components overlap in time to some degree. For example, the observed interaction between frequency and repetition in the N400 latency band may reflect a true interaction for the $\mathrm{N} 400$, or a spurious one due to contamination of the N400 latency window by an LPC that is sensitive to both frequency and repetition. The latter possibility would be obtained if the LPC began earlier for repeated than for new low-frequency words: the 300-500 measure for repeated words would include some portion of the LPC while the same window for new words would not.

One indication that the 300-500 latency window included both the N400 and the LPC comes from an analysis of the scalp distributions of the two components. An analysis of the 500-900 window using frequency, repetition, recording site by hemisphere (left versus right, midline electrodes excluded), and recording site in the anterior-posterior dimension (four levels) showed a leftsided predominance for the LPC repetition effect [repetition $\times$ laterality: $F(1,37)=13.2, p<.001]$. The asymmetry of the repetition effect in the 300-500 latency window was not statistically significant, but in the same direction of being larger on the left $[F(1,37)=3.67$, $p=.06] .^{4}$ This left-greater-than-right asymmetry in the N400 latency window is inconsistent with the N400's typical laterality of being larger over the right, and is due solely to the later portion of the $\mathrm{N} 400$ latency band (Kutas \& Hillyard, 1982; Kutas, Van Petten, \& Besson, 1988). From 300 to $400 \mathrm{msec}$ poststimulus, the right-greaterthan-left asymmetry more typical of $\mathrm{N} 400$ effects predominates [repetition $\times$ laterality: $F(1,37)=12.3, p<.0001$ ] From 400 to $500 \mathrm{msec}$, the left-greater-than-right asymmetry characteristic of the LPC in this experiment predominates $[F(1,37)=15.9, p<.0005]$.

Another test of whether the apparent frequency by repetition interaction in N400 amplitude is genuine or due to an overlapping LPC is to examine a condition where the LPC is small in amplitude. Reference to Figure 6 shows that the LPC is smallest for short-lag multiple repetitions, and that the difference between high- and low-frequency words is small here as well. Contrasting

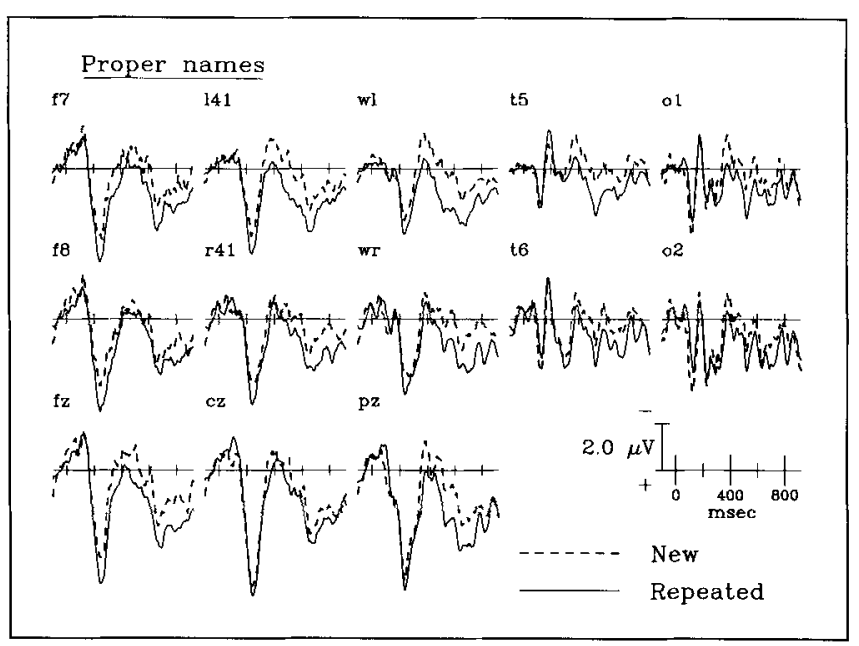

Figure 7. Grand average ERPs across 40 subjects, elicited by names of persons presented for the first time, and when repeated.

this repetition condition to new words in the original N400 latency window of 300-500 reveals no interaction between frequency and repetition $[F(1,37)=1.67]$, only a main effect of repetition $[F(1,37)=31.7, p<.0001]$.

Overall, these analyses indicate that (1) word repetition has an equivalent effect on the N400 elicited by high- and low-frequency words. (2) The LPC elicited by low frequency words begins earlier for those repeated than for new words, and (3) the two repetition effects have opposite patterns of lateral asymmetry; the N400 effect is larger over the right and the LPC effect is larger over the left.

\section{A Different Kind of Word, a Different Kind of Repetition Effect?}

The preceding analyses were based on something less than half of the words in the six experimental texts. Closed-class or function words account for most of the remaining half, although these were not sorted according to repetition. A few of the remaining words were proper names. In these nonfiction texts, some individuals were introduced, discussed for a paragraph or two, and then occasionally referred to at a later point. Our "name" category included only these person-names, most of which referred to nonfamous individuals unlikely to be familiar to our subjects. The small number of names permitted only a "new versus repeated" categorization (15 trials for each), rather than the more detailed analyses of repetition lag and number of repetitions applied to other words.

The ERPs elicited by new and repeated proper names are shown in Figure 7. The effect of repeating a name was monophasic, in contrast to the biphasic effect observed for other words, consisting of greater positivity throughout the latency regions of both the $\mathrm{N} 400$ and the LPC. The repetition effect was significant in both latency 
bands [300-500: $F(1,37)=7.24, p<.01 ; 500-900$ : $F(1,37)=5.23, p<.05]$.

\section{DISCUSSION}

The present data set included three distinct components of the ERP that were sensitive to word repetition in text: the earliest one peaking at $200 \mathrm{msec}$ poststimulus (possibly the same as the P2), the N400, and a late positivity. We will discuss each in turn, with emphasis on whether the different ERP components can be characterized in terms of the "lexical" and "episodic" components hypothesized to contribute to behavioral indices of word repetition.

\section{Early Effect (P2 Enhancement?)}

We note the early (peaking at $200 \mathrm{msec}$ ) enhanced positivity with repetition primarily because ERP repetition effects that precede the $\mathrm{N} 400$ have been reported before, but have proven rather elusive and not subject to experimental control. Rugg (1987) initially noted a repetition effect in the same latency region as that reported here; this early effect was evident in the ERPs elicited by both words and orthographically legal nonwords repeated immediately (i.e., lag 0).5 Nagy and Rugg (1989) replicated this effect for immediate repetitions, but did not observe it when there was a repetition lag of six intervening words. However, several other experiments, including some with a condition of immediate repetition, have not yielded any effect of repetition preceding the $\mathrm{N} 400$ (Bentin \& Peled, 1990; Karayanidis et al., 1991; Rugg et al., 1988; Rugg \& Nagy, 1987, 1989). Moreover, the initial reports described an early repetition effect that was of opposite polarity to that reported here, an apparent diminution of the $\mathrm{P} 2$ with repetition rather than an enhancement. The factors controlling this early component are thus unknown at present. Fortunately, we have a more consistent data base from which to interpret the impact of repetition on the $\mathrm{N} 400$ and its relationship to theoretical accounts of word repetition phenomena.

\section{N400 Component}

Our knowledge of the N400 to date characterizes it as a rather ubiquitous marker of lexical processing: N400s are elicited by words in lists, sentences, and text, and within any experimental task that encourages the processing of letter strings as words, or at least potential words. Thus, real words have elicited N400s in all tasks used thus far, with the exception of one that was based solely on the physical characteristics of the stimuli (judgment of upper versus lower case letters; Rugg et al., 1988; see also Kutas \& Hillyard, 1980a). Orthographically, illegal nonwords elicit little or no N400 activity, but legal nonwords do, presumably because illegal nonwords can be rejected after relatively shallow nonlexical processing
(Rugg, 1983; Rugg \& Nagy, 1987; Smith \& Halgren, 1987). An analogous result holds for the auditory modality in that pronounceable nonwords elicit N400s but speech sounds played backward do not (Holcomb \& Neville, 1990). Given that the stimuli and task are configured so as to elicit N400s, the default amplitude is high, and experimental manipulations can only reduce it. The experimental manipulations that reduce $\mathrm{N} 400$ amplitude are several: word repetition in lists, word repetition in text, sentence repetition, prior semantic associates in lists, prior semantic associates in sentences, and the propositional content of a preceding sentence fragment (Fischler, Boaz, Childers \& Perry, 1985; Van Petten, 1989). To date, semantic influences on N400 amplitude have proved fairly resistant to task manipulations (see Holcomb, 1988; Kutas \& Hillyard, 1989; Kutas \& Van Petten, 1988), as one would expect given that semantic analysis is the overwhelmingly typical mode of analysis for the written word, and hence the most plausible default. Phonological similarity between written words will reduce N400 amplitude if this nontypical mode of analysis is critical to the experimental task (Kramer \& Donchin, 1987; Rugg, 1984).

The list of variables that have been shown to influence N400 amplitude indicates that it shares one attribute of the logogen- type units central to many models of word recognition: a somewhat indiscriminate collection of evidence for the presence of a particular word. In this respect, the behavior of the $\mathrm{N} 400$, in the present experiment, is in accord with an abstractionist account of word repetition effects.

As reviewed earlier, a dozen ERP studies have now documented that $\mathrm{N} 400$ amplitude is reduced by word repetition in lists when the lag time between occurrences is something less than $2 \mathrm{~min}$. The present data have shown that the same is true of word repetition in text, wherein repetition is not an obvious part of the experiment, but occurs for the usual reasons that words are repeated: to maintain reference, or simply because the same word is the most apt in more than one place. Relative to new words, N400 amplitude was reduced in all of the repetition conditions, but less so for the first repetition following a long lag. In lists, the $\mathrm{N} 400$ repetition effect seems to disappear sometime between lags of 2 and $15 \mathrm{~min}$. We do not know if repetition effects will prove more persistent in text; our long-lag condition ranged from 21 to 1500 intervening words but generally spanned less than $15 \mathrm{~min}$ of reading time.

Normative word frequency had no impact on the N400 to new or to repeated words in the present analyses. In general, N400 amplitude is sensitive to word frequency under conditions in which there is little or no contextual support for the eliciting words, namely for unrepeated and unrelated words in lists, or words occurring near the beginning of isolated sentences (Smith \& Halgren, 1987; Rugg, 1990; Van Petten \& Kutas, 1990, 1991a). In cases where a frequency effect is observed for initial 
presentations, word repetition and frequency have interactive effects on N400 amplitude (Besson et al., 1991; Rugg, 1990; Smith \& Halgren, 1987). In the present experiment, all words were subject to some degree of contextual support from the surrounding discourse so that even new words showed no frequency effect. Under this condition of initial equivalence between high- and low-frequency words, repetition influenced the N400s elicited by the two frequency classes to the same degree. So there was no indication that the process indexed by the N400 maintained a hidden record of a word's longterm history of occurrence, only a single cumulative record reflecting both short- and long-term occurrences as well as the current semantic context. The N400's sensitivity to repetition lag time is also consistent with the notion of an activation function that includes some decay over time.

Of course, this analogy between N400 amplitude and the activity of theoretical word-detector units should not be carried too far. Some models that specify logogen units situate them within a modular mental lexicon; this feature is inconsistent with the N400's observed sensitivity to conceptual/propositional context. A serious exposition of the relationship between a population of cells/ synapses that is capable of producing a voltage field at the scalp and a model of lexical representation would take us far afield of our present concerns. The primary sense in which the $\mathrm{N} 400$ follows the predictions of a logogen- style account of word repetition effects is simply that frequency and repetition affect its amplitude in the same way, as if acting through the same mechanism.

In contrast to an abstractionist, logogen-style account of word frequency and repetition phenomena, an episodic account would place greater emphasis on the similarity or dissimilarity between current and prior contexts in which the same word appeared, and less emphasis on the time elapsed since the last occurrence. The present data set and the word list studies reviewed earlier converge to indicate that the $\mathrm{N} 400$ repetition effect is more susceptible to temporal factors than one would expect from a process driven by prior episodic traces. However, a stronger test of the episodic account is to determine whether repetition effects still occur when the context is altered between the first and second presentations of a word. But it is not obvious exactly what should be subsumed by the term "context." For instance, the relevant "context" included in the memory for a particular episode might be defined very broadly with regard to a memory for a given word, encompassing the particular words which immediately preceded the word in question (as in a word list), the more general topic of the discourse (as in text or conversation), and the spatial/temporal context (e.g., in a laboratory experiment versus outside the laboratory). Uncertainty about which of these contextual aspects we can reasonably expect to be a part of an episodic memory makes the strong test of the episodic account difficult to evaluate despite its apparent simplicity. Repetition studies conducted in different laboratories have implemented various change-of-context manipulations: changing the preceding single word (Masson \& Freedman, described in Carr et al., 1989), changing the simultaneously presented word (Carroll \& Kirsner, 1982), alternating between normal and scrambled text (Dixon \& Rothkopf, 1979; Levy \& Begin, 1984), and testing the subject in different rooms of the laboratory (Jacoby, 1983). These manipulations have produced variable results, some favoring the episodic account in that a change of context reduced the repetition effect, and some favoring an abstractionist account in that a change of context had little impact.

We would suggest that the most ecologically valid aspect of a word's context, and thus the most likely to be part of an episodic trace, is the topic of the discourse in which it appears. The present study did not manipulate this variable but the paradigm used would lend itself easily to a change-of-context manipulation. A firm identification of the $\mathrm{N} 400$ repetition effect with nonepisodic processes will await future research of this sort.

\section{Late Positive Component}

Like the $\mathrm{N} 400$, the late positive component responds to both normative word frequency and repetition. Unlike the $\mathrm{N} 400$, the pattern of results for LPC amplitude in the present study showed an interaction between normative and experimental frequency. This component became the largest for low-frequency words on initial presentation and became smaller with repetition.

The repetition-induced reduction in LPC amplitude observed here is in stark contrast to the results of listbased experiments wherein repetition increases the amplitude of a late positive component. The present textbased results are particularly at odds with the list results of Rugg (1990) who also observed a larger LPC for lowthan high-frequency words, but only when these were repeated and not when they were new. On the basis of those results, Rugg proposed that the LPC reflected the discrepancy between a repeated item's local familiarity (due to repetition within the experiment) and its baseline familiarity (determined by normative frequency of occurrence). This account of the LPC will not explain the present pattern of results. With multiple repetitions, the local familiarity of a low-frequency word can only become greater, generating a wider gap between local and baseline frequencies. Within Rugg's framework, this situation should lead to an increase in LPC amplitude with repetition rather than the decrease that we observed.

In word list experiments, the LPC repetition effect has persisted across much longer repetition lags than the N400 (Fischler, Boaz, McGovern, \& Ransdell, 1987; Rugg, 1990; Rugg \& Nagy, 1989). In our data, the elapsed time between repetitions was not a critical factor in determining LPC amplitude. Rather, the number of times a word 
had recurred influenced the LPC; the amplitude of this component was reduced only after multiple repetitions.

The LPC difference between high- and low-frequency words on initial presentation indicates that the LPC is not specific to repetition. Its sensitivity to both normative word frequency and experimental repetition does, however, suggest that this component reflects some aspect of memory. Exactly what aspect is a matter of speculation for the moment. The proposal that we find most congenial is that the LPC indexes the updating of working memory with information retrieved from long-term memory. The amplitude of the LPC is some function of the extent of the retrieval and/or updating. Below, we elaborate on how this characterization handles three outstanding questions raised by the current data set. While speculative, our hypothesis is testable, and we sketch how the relevant experiments might look. We conclude with an examination of the relationship between the present repetition/frequency LPC and late positive components recorded in ERP experiments explicitly designed to investigate memory processes.

\section{Why Does Word Repetition Yield Opposite Effects on LPC Amplitude in Texts Versus Lists?}

The memory demands imposed by a comprehension task as compared to tasks used in word list experiments may account for the discrepancy between the present results and those of other ERP experiments. Successful discourse processing requires that the meaning of each new word be retrieved from memory, and its relevant connotation be integrated with the preceding text to modify the reader's working model of the discourse content. The high comprehension scores of the subjects in this experiment (see Methods) suggest that they were actively engaged in these tasks. Both the retrieval and updating demands are likely to be less when a word recurs in text. To the extent that a concept is already represented in one's mental model of an ongoing discourse, re-presentation of the word referring to that concept will require fewer of the word's attributes to be newly retrieved from long term memory, and less updating of the mental model. The decrease in LPC amplitude with repetition may then be a consequence of the fact that discourse structure assigns lighter mnemonic demands to repeated rather than to new words.

The memory requirements and strategies applied to word lists are clearly somewhat different from those used in text comprehension. Two of the tasks used in ERP list experiments, lexical decision and classification according to semantic category (Bentin \& Peled, 1990; Karayanidis, Andrews, Ward, \& McConaghy, in press; Nagy \& Rugg, 1989; Rugg, 1987, 1990; Rugg, Furda, \& Lorist, 1988; Rugg \& Nagy, 1987, 1989), encourage the discrete processing of each individual word; no record of the stimulus word need be maintained in working memory once the task decision has been made. The retrieval demands imposed by these tasks are also somewhat lighter than those imposed by text integration; even semantic categorization (e.g., "is this the name of an animal?") requires that only a minimal definition of a word be retrieved whereas a more detailed specification might be required to apprehend the meaning of a word in context. In the present framework, the small LPC elicited by new words in lists would thus be attributed to the light load imposed on both retrieval and updating processes. Why then should a repeated list word elicit a larger LPC than a new word? We would suggest that the subjects are retrieving the memory of the word's prior occurrence and perhaps noting the repetition. Subjects may recall prior presentations in an attempt to discover the pattern of the experimental materials, or because recalling their prior task decisions on the same items improves their efficiency with future decisions. In this regard, the repetition of a word in a list resembles a new word in text in its engagement of retrieval and updating processes. The memory demands associated with a given concept in text are initially high, but decline as the concept becomes well established in the reader's working memory. Processing a new word in a list places few demands on either retrieval or the maintainance of working memory, but repetitions encourage the retrieval of prior occurrences.

This characterization of the difference between texts and lists suggests that the direction of the LPC word repetition effect can be manipulated independently of the text/list nature of the experimental materials. If list words were repeated several times with a short enough lag so that the last presentation was still in working memory, the present framework would predict a smaller LPC for the third than the second presentation due to the decreased retrieval demand. Conversely, subjects reading text could be assigned a task wherein the memory demands increased rather than declined with repetition, such as indicating whether a word had occurred before, and if so, how often.

\section{Why Were Repetition Effects for Proper Names Different Than Those for Other Words?}

The repetition effect for proper names was similar to that observed for words in list-based experiments (Bentin \& Peled, 1990; Karayanidis, Andrews, Ward, \& McConaghy, 1991; Nagy \& Rugg, 1989; Rugg, 1987, 1990; Rugg, Furda, \& Lorist, 1988; Rugg \& Nagy, 1987, 1989; Smith \& Halgren, 1989) in that repeated names elicited a larger LPC than new names. We believe that the memory differences between the first and subsequent presentations of the names in our experimental texts closely parallel those for new versus repeated words in lists. An example from one of the experimental texts will clarify this point. In the story about American millionaires, an individual named Edith Hill is first introduced at word 565 : 
More typical than the Du Ponts or the Mellons is Edith Hill of Acton, Massachusetts, who twelve years ago was a divorced welfare mother with a highschool education trying to support her three children. She learned how to sell real estate ...

Edith is the topic of the next three sentences, being referred to by the pronouns "she" and "her." When she is reintroduced at word 1140 , the full proper name is again used:

With their fortunes tied up in businesses or real estate, many can find themselves strapped for cash. New millionaire real-estate agent Edith Hill, for example, says her family lives on fifty thousand to sixty thousand dollars a year.

Edith makes her final appearance at the end of the millionaire story, at word 1306 :

"If I had a lot more money, I would take a month off and go to the ocean every summer," says Edith Hill. How much more is a lot more? Her reply: "It's probably just a dream."

The first relevant aspect of this discourse structure is that, on initial presentation, the unfamiliar name is nearly devoid of content. The reader is expected to retrieve only the most minimal information from memory to determine the gender of the individual. Both the retrieval and updating requirements are thus very low for the initial presentation of a name. The second relevant aspect is that the proper name is repeated only when an individual is reintroduced after some intervening material. At this time, the reader is expected to retrieve the prior description and integrate the new material with the old. For proper names, memory demands thus increase with repetition.

This characterization of the proper name effect predicts very different results if familiar names were used. The initial presentation of a famous or familiar name should elicit a large LPC, if comprehension demanded that the reader access his or her prior knowledge about the individual.

\section{Why Is the LPC Larger for Low-Frequency Words?}

This is perhaps the most difficult question raised by the present results and by Rugg's (1990) report that, on repetition, low-frequency words elicit larger LPCs than high-frequency words. Contrary to the list experiment, we have seen that the LPC frequency effect is not contingent on repetition. It is also worth noting that pure frequency of occurrence is probably not the critical factor since, by this criterion, most of our proper names would be considered low frequency. However, for words other than names, factors correlated with frequency of occurrence may influence LPC amplitude. One such factor is a difference in the lexical semantics of high- and lowfrequency words.

High-frequency words are more polysemous than low frequency words (Lee, 1990; Zipf, 1945). Put another way, the meaning of a common word in isolation will be relatively broad and vague so that much of the specific sense carried by such a word in discourse will be filled in or constructed on the basis of the surrounding context (Anderson \& Shifrin, 1980; Schreuder \& Flores d'Arcais, 1989). So for instance, the different uses of the verb "cut" seem to share a very abstract sense of separating or opening something, but this sense receives different instantiations in phrases such as cut a slice of bread, cut into traffic, cut class, cut the calf from the berd, cut off my question, or cut off the circulation. The precise meaning of a high-frequency word in discourse will then be only partially determined by retrieval of its definition from memory, the rest will need to be constructed from the context. By contrast, low-frequency words have a narrower scope of meaning that is more rigidly defined and less variable from use to use (compare caffeine, clinic, tea, solvent to $c u t){ }^{6}$ As compared to a high-frequency word, the interpretation of a low frequency word may then rely less on the immediate context, and more on the retrieval of prior encounters with that word. Given our description of the LPC as an index of episodic retrieval processes, these semantic differences between high- and low-frequency words would result in a larger LPC for low- than high-frequency words in situations in which the specific meaning of a high-frequency word is partially derived from the immediate context, but the specific meaning of a low-frequency word is largely remembered.

We have been attempting to provide an integrated account of LPC repetition effects wherein at least some portion of the late positive component is taken to reflect retrieval from long-term memory. The information retrieved may concern preexperimental (e.g., semantic attributes) or intraexperimental knowledge (e.g., a prior occurrence of the same word, or information acquired about a particular individual, if the word is a name). The retrieval of semantic information is likely to predominate in the case of a comprehension task, and we have argued that the greater distinctiveness or specificity of low-frequency meanings provides an explanation of the larger late positivity for low- than high-frequency words in the present data. In the Rugg (1990) lexical decision study both intraexperimental and lexical semantic differences between high- and low-frequency words may have contributed to his observation of an LPC frequency effect for repeated words only. As described earlier, the design of Rugg's study would motivate a subject's recovery of a word's initial presentation more for low- than high-frequency words. This is because the low frequency words were difficult to discriminate from nonwords, but only words were repeated so that remembering the initial 
episode would aid in the task decision that a low frequency word was indeed a real word.

As for possible semantic contributions to Rugg's LPC frequency effect, the long history of semantic priming effects in word list studies indicates that subjects undertake some semantic processing under most conditions. The existence of Stroop interference effects, wherein semantic processing is actively detrimental to the performance of the experimental task, provides another argument for the same conclusion. The depth of such processing may depend on how much latitude the assigned task allows. The initial phases of word processing mandatory for a lexical decision are clearly somewhat easier for repeated rather than for new words, as evidenced by faster reaction times, lower error rates, and reduced N400 amplitudes. In the present study, the conjunction of a smaller $\mathrm{N} 400$ with an earlier onset of the LPC frequency effect for repeated words argues that the process indexed by the LPC is engaged earlier when the initial phases of lexical processing are easier. In Rugg's study, the need for less effort in making lexical decisions for repeated words may then have allowed more latitude for the recovery of the semantic detail which we have suggested contributes to the LPC frequency effect.

\section{Late Positivities in Memory Studies}

Our characterization of the LPC repetition/frequency effect in terms of the retrieval of information from longterm memory, and consequent updating of working memory is a novel one, but the link between late positivities and mnemonic processes is not. Donchin (1981; Donchin \& Coles, 1988) has long maintained that the P300 elicited in a variety of experimental situations reflects the updating of working memory. He has focused on the updating elicited by the event to which the P300 is time locked, whereas we have focused on the working memory changes triggered by retrieval of information from long-term memory. Donchin's proposal has been controversial (see Verleger, 1988) and we too are hesitant to assign every P300 in every task to memory processes. Even where memory processes contribute to the P300 recorded at the scalp, they may not be the sole contributing factor. However, it has been clear that at least a small amplitude positivity fluctuates systematically with memory processes.

Several ERP studies have shown that the amplitude of a late positivity elicited by words on initial presentation is predictive of subsequent memory performance for those words (Fabiani, Karis, \& Donchin, 1986, 1990; Karis, Fabiani, \& Donchin, 1984; Neville, Kutas, \& Chesney \& Schmidt, 1986; Paller, 1990; Paller, Kutas, \& Mayes, 1987; Paller, Kutas, Shimamura, \& Squire, 1987; Paller, McCarthy, \& Wood, 1988; Sanquist, Rohrbaugh, Syndulko, \& Lindsley, 1980). The typical sequence of events in these experiments has been to present the words in conjunction with some orienting task, administer a recall, cued-recall, or recognition test, and then sort the ERPs elicited during the first phase according to memory performance. Words that will later be remembered are associated with larger positivities than words that will be forgotten. This effect is not specific to words as it has also been observed when pictures served as the stimuli (Friedman \& Sutton, 1987).

Because this late positive difference emerges from ERPs recorded on initial presentation (in some cases, before the subjects knew that there would be a memory test), there is general agreement that the "DM" (Difference based on subsequent Memory) reflects processes leading to the formation of a memory trace for a particular word. Given that the stimulus words are all within the subjects' vocabularies, the relevant memory is for a particular episode, namely the fact that the word occurred within an experimental list. Beyond these general conclusions, there has been a lack of consensus about the functional significance of the DM, and particularly about its relationship to late positive ERP components in general (see Fabiani et al., 1986; Donchin \& Coles, 1988; Kutas, 1988; Paller, Kutas, \& Mayes 1987; Halgren \& Smith, 1987 for differing views and discussion).

One finding in the DM literature is supportive of our suggestion that at least some portion of a late positive component reflects memory retrieval. This is the finding that semantic orienting tasks (e.g., "is this living or nonliving?") result in larger positivities and a larger DM effect than orienting tasks based on stimulus features that require less access to prior knowledge, such as counting the number of vowels in a word (Paller, Kutas, \& Mayes, 1987; Sanquist et al., 1980). Given that "elaboration" (i.e., linking a current stimulus to prior knowledge) has generally been found to yield better subsequent memory performance for the stimulus (Craik \& Tulving, 1975), it may be that the larger positivity for subsequently remembered items was due to their elaborative encoding at input.

One group of ERP memory researchers has, however, argued for quite the opposite relationship between the DM effect and elaborative encoding of the stimuli on input. In an experiment in which subjects were forewarned of the upcoming memory task during the study phase, Karis et al. (1984) asked subjects to introspect on their memorization strategies. Subjects who reported a "rote" strategy showed large DM effects when the study phase ERPs were sorted according to subsequent recall, whereas subjects who reported trying to link the stimulus words to people or songs that they knew showed little DM. Fabiani et al. (1990) replicated this effect in an experiment in which subjects were explicitly instructed to use rote or elaborative memorization strategies. These researchers thus concluded that the DM effect reflected nonelaborative encoding during the study phase. However, another interpretation is possible, namely that some portion of the LPC elicited on input is due to elaboration (e.g., the retrieval and linkage of prior knowledge to the 
current stimulus), but when all stimuli receive this treatment, it is no longer the deciding factor for subsequent performance. For subjects who primarily use a rote strategy, those few stimuli that received some elaborative processing at input (and thus elicited larger positivities at that time) will have a great advantage at recall. Thus, when sorted according to subsequent memory performance, the words recalled by only the "rote" subjects will exhibit larger positivities than the words forgotten. This interpretation would also predict that "elaborative" subjects would produce larger positivities than "rote" subjects for all words regardless of subsequent performance. This was the direction of the data in the experiment of Fabiani et al. (1990).

\section{Relation between ERP Word Repetition and Memory Studies}

The existence of two (or three) distinct ERP components sensitive to word repetition is consistent with theories proposing more than one locus for the facilitation of behavioral performance with repetition. We have suggested that the $\mathrm{N} 400$ reflects fundamental processes of word identification but that, based on the dissociations between word repetition in text versus lists and between common words versus names, the late positive component reflects the extended retrieval of semantic and episodic information and the integration of that information with the contents of working memory. These latter processes are more likely to have an impact on the ability to recall or recognize the eliciting word at a later time than are the processes reflected in the N400, except to the extent that these processes can begin sooner if basic word identification is made easier. Some support for this description of the two components arises from the finding of Neville et al. (1986; see also Kutas, 1988) that words that were semantically incongruent on initial presentation (e.g. "A type of furniture: dog") elicited larger LPCs if subsequently recognized than unrecognized, but equivalent $\mathrm{N} 400 \mathrm{~s}$ regardless of later memory performance. However, in the same study it was found that this DM effect for recognized words began earlier in the poststimulus epoch if the word was congruent with its context and elicited a smaller N400.

Although important for subsequent recognition or recall performance, the "deep" or "elaborative" processing that we attribute to the LPC has less consequence for other measures of retention, such as repetition priming effects on word-stem completion (Graf \& Mandler, 1984). Paller (1990) recently analyzed the ERPs elicited by initial word presentation as a function of later performance on tests of free recall, recall cued by a word stem, and stem completion with the instructions to use "the first word that comes to mind." A significant repetition priming effect was obtained for stem completion performance in that subjects tended to use the words that had been presented earlier. However, unlike the two recall measures, there was no late positive difference between subsequently "remembered" and "forgotten" words for stem completion priming. This dissociation offers tantalizing evidence that the DM effect, or perhaps late positivities in general, reflect only one variety of memory. However, a dissimilar pattern of results in a previous contrast of recall and stem completion suggests caution and a need for further research (Paller, Kutas, Shimamura, \& Squire, 1987).

Further research will be needed to understand word repetition effects alone, as well as their relation to various memory processes. However, it is clear now that more than one repetition-sensitive process exists, and that these are differentially responsive to factors such as the number of repetitions, the time between them, the linguistic context in which the word occurs, and the lexical characteristics of the word itself. If nothing else, the uncertainty of anticipating what effects might emerge in a particular situation will suggest that care be taken to avoid repetition effects in experiments where they are not factors of interest.

\section{METHODS}

\section{Subjects}

Forty native English speakers with normal or correctedto-normal vision were paid for their participation. Twenty-three were men; seventeen were women. Four were left handed; six of the right-handers had a lefthanded parent or sibling. Mean age was 22.4 years (range 18 to 41$)$.

\section{Stimuli}

The stimuli were six nonfiction texts drawn from a popular magazine (Reader's Digest) on the topics of caffeine, cold viruses, shark attacks, insomnia, sloths, and American millionaires. These ranged from 1000 to 1800 words in length.

Each text was edited to replace some sentence-intermediate words with erroneous words. The errors included outright semantic anomalies (e.g., "Attacks of this kind may be caused by a swimmer who, by accident, interrupts a courting assume, trespasses on a shark's territory or cuts off its escape route.") as well as violations of derivational and inflectional morphology (e.g., "Certain cold viruses have devised counterweapons which can turns the body against itself."). The erroneous words were placed so as to disrupt overall comprehension of the text as little as possible and occurred, on the average, every 68 words. Twenty true-false questions for each text were administered immediately after subjects had read each one. Performance on these comprehension tests ranged from 79 to $96 \%$ correct across the 40 subjects, with a mean of $89 \%$. 
All sentence-intermediate nouns, verbs, adjectives, and derived adverbs in each text (excepting the errors) were initially classified as either "high" or "low" frequency according to whether the sum of all regularly inflected forms of the word occurred with a frequency of greater or less than 30/million in the Francis and Kucera (1982) count. Thirty per million was chosen as the cutoff between high and low frequency based on previous results showing the largest ERP differences around this point of the frequency distribution (Van Petten \& Kutas, 1990). Next, words were classified as "new" or "repeated" based on whether or not they had previously occurred in the same text (later occurrences of words that had been in a previous experimental text were not included in either the "new" or the "repeated" class). For the purposes of classifying a word as new or repeated, all regularly inflected forms of a word were considered to be the same word. Repeats of a derivationally related form (e.g., "destroy" and "destruction") were excluded from both the "new" and the "repeated" categories.

Both high- and low-frequency repeated words were further divided into four classes depending on the recency of their last occurrence (or "lag" time between occurrences) and how often they had been repeated (or the "number" of repetitions). For a "short lag" repetition, the word recurred within 20 words of its last presentation; for a "long lag" repetition, more than 20 words had intervened since last occurrence. Similarly, a dichotomy was made between words repeated for the first time ("first repetitions") and additional repetitions ("second repetitions" includes second, third, and subsequent repetitions) in the same text.

The classification scheme outlined above yielded 10 stimulus conditions: (1) high-frequency new words; (2) high-frequency, short-lag, first repetitions; (3) high-frequency, long-lag, first repetitions; (4) high-frequency, short-lag, second repetitions; (5) high-frequency, longlag, second repetitions; and (6-10) the analogous categories for low-frequency words. Subsets of the words belonging to each of the ten categories were then selected for inclusion in the experiment given the constraint that mean word length be equivalent across the 10 conditions (mean length ranged from 6.9 to 7.5 characters across conditions).

A total of 2420 words met the specifications for inclusion in the experimental conditions. Mean frequency of usage was $216 /$ million (standard deviation $=383$ ) for the high-frequency words, and 10/million $(S D=13)$ for the low-frequency words. The mean number of intervening words for short-lag repetitions was 14 (standard deviation $=7$, range 0 to 19). For long-lag repetitions, the mean number of intervening words was $228(\mathrm{SD}=$ 259 , range 21 to 1500 ).

Finally, new and repeated names of persons (e.g., "Edith Hill," "Thomas Collins") were coded separately to make 12 stimulus conditions in all. The mean lag between occurrences of the same name was 287 words.

\section{Procedure}

General Procedure

Subjects were run in two sessions of approximately $3 \mathrm{hr}$ each, conducted within the same week. They read three of the six texts in each session, with the order of presentation counterbalanced across subjects. Following electrode application, subjects were seated in a comfortable chair in a quiet, electrically shielded chamber, 100 $\mathrm{cm}$ from a color monitor controlled by a PC-AT style computer. Words were presented one at a time centered within a continuously present frame to aid in eye fixation. The frame subtended 3.6 horizontal degrees and 1.1 vertical degrees of visual angle; a seven character word subtended 1.4 horizontal degrees.

Words were presented for a duration of $200 \mathrm{msec}$. There was a $3.5 \mathrm{sec}$ interval between sentences to allow subjects to blink and shift position without contaminating the electroencephalographic (EEG) data. The interword interval during each sentence was varied among three different groups of subjects. One group of 21 subjects saw one word every $400 \mathrm{msec}$ ( $200 \mathrm{msec}$ stimulus duration, 200 msec blank frame), 5 subjects were run at a rate of one word every $600 \mathrm{msec}$, and a third group of 14 subjects were run using a variable rate that depended on the length of the word being presented (range 320$680 \mathrm{msec}$, mean $480 \mathrm{msec}$ ). These rate manipulations are part of an ongoing investigation as to the impact of speed of presentation on ERP data, and in particular on whether or not it is necessary to present words at a fixed rate as opposed to a more variable one mimicking natural reading. As regards repetition effects, we found the rate manipulation to have no impact. Thus, data from the three groups have been analyzed together with "rate" serving as a factor in the statistical analyses (see also below).

\section{Electrophysiological Data Collection}

The EEG was recorded with tin electrodes mounted in a commercially available elastic cap (Electrocap International). Midline frontal $(\mathrm{Fz})$, central $(\mathrm{Cz})$, and parietal $(\mathrm{Pz})$ recording sites were used, along with lateral pairs of electrodes over the frontal $(\mathrm{F} 7, \mathrm{~F} 8)$, posterior temporal ( $\mathrm{T} 5, \mathrm{~T} 6)$, and occipital $(\mathrm{O} 1, \mathrm{O} 2)$ scalp as defined by the 10-20 system (Jasper, 1958). Two additional lateral pairs were used: (1) a temporoparietal pair that was placed $30 \%$ of the interaural distance lateral and $12.5 \%$ of the inion-nasion distance posterior to $\mathrm{Cz}$ (approximately over Wernicke's area and its right hemisphere homolog, $\mathrm{Wl}$ and $\mathrm{Wr}$ ), and (2) a central pair that was 33\% lateral to $\mathrm{Cz}$ (approximately over Brodmann's area 41, L41 and R41). An additional active electrode was placed over the right mastoid. Vertical eye movements and blinks were monitored via an electrode placed below the right eye. The scalp sites and the vertical EOG electrode were referenced to the left mastoid during the recording session, but rereferenced off-line to an average of the left 
and right mastoids (see Van Petten \& Kutas, 1988). Horizontal eye movements were monitored via a right to left bipolar montage at the external canthi of the two eyes. The EEG was amplified by a Grass Model 12 polygraph with half-amplitude cutoffs of 0.01 and $100 \mathrm{~Hz}$, digitized on-line at a sampling rate of $250 \mathrm{~Hz}$, and stored on magnetic tape along with stimulus codes for subsequent averaging. Trials with artifacts due to eye movement, muscle, or amplifier blocking were rejected prior to averaging.

\section{Electrophysiological Data Analysis}

Average ERPs were formed for each subject in each of the 12 conditions. The waveforms were quantified by measuring mean or peak voltages within selected latency windows, relative to a $100 \mathrm{msec}$ prestimulus baseline. Statistical analyses were performed with repeated measures analyses of variance (ANOVA), with experimental condition and electrode site as within-subject factors. For interactions between electrode site and experimental condition, we used the Huynh-Feldt correction for violations of sphericity (see Vasey \& Thayer, 1987). In these cases, we report the original degrees of freedom, the epsilon correction factor, and the corrected probability level. The stimulus presentation rate was entered as a between-subject factor. There were no significant interactions between stimulus rate and experimental condition in any of the analyses reported.

\section{Acknowledgments}

This work was supported by a grant from NICHD (HD22614), and $M$. Kutas was supported by an RSDA from NIMH (MH00322). We are grateful to Ron Ohst for technical support.

Reprint requests should be sent to Cyma Van Petten, Department of Psychology, University of Arizona, Tucson, AZ 85721.

\section{Notes}

1. Although it is a very complex problem to assign ERP components to neural generators on the basis of scalp distributions, distributional analyses can readily be used to make identity or nonidentity judgments. Experimental effects with different scalp distributions must be produced by different (although possibly overlapping) populations of active synapses.

2. Note that we are using the term "LPC" as a descriptive one to differentiate the latter phase of the ERP repetition effect from the earlier N400 phase, without suggesting any identification with the $\mathrm{P} 3 \mathrm{a}, \mathrm{P} 3 \mathrm{~b}$, slow wave, or other components that have been collectively titled the "late positive complex" in the ERP literature. The relationship between the late positive word repetition effect and late positive components recorded in other experimental paradigms will be taken up below and again in the Discussion.

3. It is important to note that although the LPC effects extended well beyond the point when the subsequent word was presented, they are time-locked to the word presented at time
0 in the figures. We were able to ascertain this by comparing the subjects run with a presentation rate of one word every $400 \mathrm{msec}$ to those run at a rate of one word every $600 \mathrm{msec}$ (see Methods). For both groups, the onset of the LPC frequency effect for unrepeated words was at $500 \mathrm{msec}$ poststimulus.

4. As shown in Figure 4, the N400 and LPC portions of the repetition effect had a similar distribution in the anteriorposterior dimension: small or absent frontally, intermediate amplitude at central sites, and equally large at temporoparietal (Wl, Wr), temporal (T5,T6), and occipital (O1, O2) sites. The 300-500 window thus showed a significant interaction between repetition and the anterior-posterior factor $[F(3,111)=9.98$, $\epsilon=46, p<.0001]$. For the $500-900$ window, this posterior predominance appeared as a three-way interaction between frequency, repetition, and the anterior-posterior factor because the LPC repetition effect occurred mostly for low frequency words $[F(3,111)=11.5, \epsilon=.63, p<.0001]$

5. The scalp distribution of Rugg's (1987) early effect was similar to that observed for the present effect in the anteriorposterior dimension. He did not report a lateral asymmetry whereas the present effect was distinctly larger over the right than the left. However, Rugg's study included only a single pair of lateral electrodes. These were close to our L41 and R41 locations, which showed the least degree of lateral asymmetry.

6. It is not coincidental that we chose a verb to exemplify the high-frequency class, and nouns as low-frequency examples since the low frequency words used in the texts were predominantly nouns rather than verbs ( 59 vs. $16 \%$ ), while the highfrequency set contained a larger proportion of verbs ( $45 \%$ nouns, $32 \%$ verbs). It has been shown that, independent of frequency, nouns are less susceptible to semantic influence from the surrounding context than are verbs (Gentner, 1981; Gentner \& France, 1988).

\section{REFERENCES}

Anderson, R. C., \& Shifrin, Z. (1980). The meaning of words in context. In R. J. Spiro, B. C. Bruce, \& W. F. Brewer, Theoretical issues in reading comprebension (pp. 331-348). Hillsdale, N.J.: Lawrence Erlbaum.

Arezzo, J. C., Vaughan, H. G., Kraut, M. A., Steinschneider, M., \& Legatt, A. D. (1986). Intercranial generators of event-related potentials in the monkey. In R. Q. Cracco \& I. BodisWollner (Eds.), Evoked potentials. Frontiers of clinical neuroscience (Vol. 3, pp. 174-189). New York: Alan Liss.

Balota, D. A. (1990). The role of meaning in word recognition. In D. A. Balota, G. B. Flores d'Arcais, \& K. Rayner (Eds.), Comprebension processes in reading (pp. 9-32). Hillsdale, NJ: Lawrence Erlbaum.

Bentin, S. (1987). Event-related potentials, semantic processes, and expectancy factors in word recognition. Brain and Language, 31, 308-327.

Bentin, S., McCarthy, G., \& Wood, C. C. (1985). Event-related potentials associated with semantic priming. Electroencephalograpby and Clinical Neurophysiology, 60, 343-355.

Bentin, S., \& Peled, B. S. (1990). The contribution of taskrelated factors to ERP repetition effects at short and long lags. Memory $\&$ Cognition, 18, 359-366.

Besson, M., Kutas, M., \& Van Petten, C. (1986). Effect of semantic expectancy upon information retrieval. Psychophysiology, 23, 425-426.

Besson, M., Kutas, M., \& Van Petten, C. (1990). ERP signs of semantic congruity and word repetition in sentences. In C. H. M. Brunia, A. W. K. Gaillard, and A. Kok, Psycbophysiological Brain Researcb (Vol. 1, pp. 259-262). Tilburg, Germany: Tilburg University Press. 
Besson, M., Kutas, M., \& Van Petten, C. (1991). An eventrelated potential (ERP) analysis of semantic congruity and repetition effects in sentences. In press.

Carr, T. H., Brown, J. S., \& Charalambous, A. (1989). Repetition and reading: Perceptual encoding mechanisms are very abstract but not very interactive. Joumal of Experimental Psychology: Leaming, Memory, and Cognition, 15 $763-778$.

Carroll, M., \& Kirsner, K. (1982). Context and repetition effects in lexical decision and recognition memory. Joumal of Verbal Leaming and Verbal Behavior, 21, 55-69.

Chiappa, K. H. (1983). Evoked potentials in clinical medicine. New York: Raven Press.

Cracco, R. Q., \& Bodis-Wollner, I. (1986). Evoked potentials. frontiers of clinical neuroscience (Vol. 3). New York: Alan Liss.

Craik, F. I. M., \& Tulving, E. (1975). Depth of processing and the retention of words in episodic memory. Joumal of Experimental Psychology: General, 104, 268-294

Dixon, P., \& Rothkopf, E. Z. (1979). Word repetition, lexical access, and the process of searching words and sentences. Joumal of Verbal Leaming and Verbal Bebavior, 18, 629644.

Donchin, E. (1981). Surprise! . . Surprise? Psychophysiology, $18,493-513$.

Donchin, E., \& Coles, M. G. H. (1988). Is the P300 component a manifestation of context updating? Behavioral and Brain Sciences, $11,357-428$.

Fabiani, M., Karis, D., \& Donchin, E. (1986) P300 and recall in an incidental memory paradigm. Psychopbysiology, 23, 298-308.

Fabiani, M., Karis, D., \& Donchin, E. (1990). Effects of mnemonic strategy manipulation in a Von Restorff paradigm. Electroencephalography and Clinical Neurophysiology, 75, 22-35.

Feldstein, P., Smith, M. E., \& Halgren, E. (1987, June). Cross modal repetition effects on the N4. Paper presented at the Fourth International Conference on Cognitive Neuroscience, Dourdan, France

Feustel, T. C., Shiffrin, R. M., \& Salasoo, A. (1983). Episodic and lexical contributions to the repetition effect in word identification. Joumal of Experimental Psychology: General, 112, 309-346.

Fischler, I., Boaz, T., Childers, D.G., \& Perry, N.W., Jr. (1985). Lexical and propositional components of priming during sentence comprehension. Psychopbysiology, 22, 576 (Abstract).

Fischler, 1., Boaz, T. L., McGovern, J., \& Ransdell, S. (1987). An ERP analysis of repetition priming in bilinguals. In: R. Johnson, Jr., J. W. Rohrbaugh, \& R. Parasuraman (Eds.), Current trends in event-related potential research. Electroencephalograpby and Clinical Neurophysiology, Supplement 40 (pp. 388-393). Amsterdam: Elsevier.

Forster, K. I. (1985). Lexical acquisition and the modular lexicon. Language and Cognitive Processes, 1, 87-108.

Francis, W. N., \& Kučera, H. (1982). Frequency analysis of English usage: Lexicon and grammar. Boston: Houghton Mifflin.

Friedman, D., \& Sutton, S. (1987). Event-related potentials during continuous recognition memory. In: R. Johnson, Jr., J. W. Rohrbaugh, \& R. Parasuraman (Eds.), Current trends in event-related potential research. Electroencephalography and Clinical Neurophysiology, Supplement 40 (pp. 316 321): Amsterdam: Elsevier.

Gentner, D. (1981). Some interesting differences between verbs and nouns. Cognition and Brain Theory, 4, 161-178.

Gentner, D., \& France, I. M. (1988). The verb mutability effect: studies of the combinatorial semantics of nouns and verbs. In S. L. Small, G. W. Cottrell, \& M. K. Tanenhaus (Eds), Lexical ambiguity resolution: Perspectives from psycholinguistics, neuropsychology, and artificial intelligence (pp. 343-382). San Mateo, CA: Morgan Kaufmann.

Graf, P., \& Mandler, G. (1984). Activation makes words more accessible, but not necessarily more retrievable. Joumal of Verbal Leaming and Verbal Bebavior, 23, 553-568.

Halgren, E. (1990). Insights from evoked potentials into the neuropsychological mechanisms of reading. In A. B. Scheibel $\&$ A. F. Weschler (Eds.), Neurobiology of higher cognitive function. New York: Guilford Press

Halgren, E., \& Smith, M. E. (1987). Cognitive evoked potentials as modulatory processes in human memory formation and retrieval. Human Neurobiology, 6, 129-139.

Hillyard, S. A., \& Kutas, M. (1983). Electrophysiology of cogni tive processing. Annual Review of Psycbology, 34, 33-61.

Hillyard, S. A., \& Picton, T. W. (1987). Electrophysiology of cognition. In F. Plum (Ed.), Handbook of physiology: The nervous system (Vol. V, Part 2, pp. 519-584). Bethseda: American Physiological Society.

Holcomb, P. J. (1988). Automatic and attentional processing: An event-related brain potential analysis of semantic processing. Brain and Language, 35, 66-85.

Holcomb, P. J., \& Neville, H. J. (1990). Auditory and visual semantic priming in lexical decision: a comparison using event-related brain potentials. Language and Cognitive Processes, 5, 281-312.

Horst, R. L., Johnson, R., Jr., \& Donchin, E. (1980). Event- related brain potentials and subjective probability in a learn ing task. Memory and Cognition, 8, 476-488.

Jacoby, L. L. (1983). Remembering the data: Analyzing interac tive processes in reading. Joumal of Verbal Learning and Verbal Bebavior, 22, 485-508.

Jacoby, L. L., \& Dallas, M. (1981). On the relationship between autobiographical memory and perceptual learning. Joumal of Experimental Psychology: General, 110, 306-340.

Jasper, H. H. (1958). The ten-twenty electrode system of the International Federation. Electroencephalograpby and Clinical Neurophysiology, 10, 371-375.

Karayanidis, F., Andrews, S., Ward, P. B., \& McConaghy, N. (1991). Effects of inter-item lag on word repetition: An event-related potential study. Psychopbysiology. In press

Karis, D., Fabiani, M., \& Donchin, E. (1984). "P300" and memory: Individual differences in the von Restorff effect. Cognitive Psychology, 16, 177-216.

Kramer, A. F., \& Donchin, E. (1987). Brain potentials as indices of orthographic and phonological interaction during word matching. Joumal of Experimental Psychology. Learning, Memory, and Cognition, 13, 76-86.

Kolers, P. (1973). Remembering operations. Memory and Cognition, 3, 347-355

Kolers, P. (1976). Reading a year later. Joumal of Experimental Psychology: Human Leaming and Memory, 2, 554-565.

Kučera, H., \& Francis, W. N. (1967). Computational analysis of present-day American English. Providence, RI: Brown University Press.

Kutas, M. (1988). Review of Event-Related Potential Studies of Memory. In M. S. Gazzaniga (Ed.), Perspectives in memory research (pp. 181-218). Cambridge: MIT Press.

Kutas, M., \& Hillyard, S. A. (1980a). Event-related brain potentials to semantically inappropriate and surprisingly large words. Biological Psychology, 11, 99-116.

Kutas, M., \& Hillyard, S. A. (1980b). Reading senseless sentences: Brain potentials reflect semantic incongruity. Science, 207, 203-205.

Kutas, M., \& Hillyard, S. A. (1980c). Reading between the lines: Event related brain potentials during natural sentence processing. Brain and Language, 11, 354-373. 
Kutas, M., \& Hillyard, S. A. (1982). The lateral distribution of event-related potentials during sentence processing. Neuropsychologia, 20, 579-590.

Kutas, M., \& Hillyard, S. A. (1984). Brain potentials during reading reflect word expectancy and semantic association. Nature (London), 307, 161-163.

Kutas, M., \& Hillyard, S. A. (1989). An electrophysiological probe of incidental semantic association. Joumal of Cognitive Neuroscience, 1, 38-49

Kutas, M., Hillyard, S. A., \& Gazzaniga, M. S. (1988). Processing of semantic anomaly by right and left hemispheres of commissurotomy patients: Evidence from event-related brain potentials, Brain, 111, 553-576.

Kutas, M., Lindamood, T., \& Hillyard, S. A. (1984). Word expectancy and event-related brain potentials during sentence processing. In S. Kornblum \& J.Requin (Eds.), Preparatory states and processes (pp. 217-238). Hillsdale, NJ: Lawrence Erlbaum.

Kutas, M., \& Van Petten, C. (1988). Event-related brain potential studies of language. In P. K. Ackles, J. R. Jennings and M. G. H. Coles (Eds.), Advances in psychophysiology (Vol. 3, pp. 139-187). Greenwich, CT: JAI Press.

Kutas, M., Van Petten, C., \& Besson, M. (1988). Event-related potential asymmetries during the reading of sentences. Electroencephalography and Clinical Neurophysiology, 69, 218- 233.

Lee, C. J. (1990). Some hypotheses concerning the evolution of polysemous words. Journal of Psycholinguistic Research, 19, 211-219.

Levy, B. A., \& Begin, J. (1984). Proofreading familar text: Allocating resources to perceptual and conceptual processes. Memory and Cognition, 12, 621-632.

Mandler, G. (1980). Recognizing; The judgement of previous occurrence. Psychological Review, 87, 252-271.

McCallum, W. C., Farmer, S. F., \& Pocock, P. K. (1984). The effects of physical and semantic incongruities on auditory event- related potentials. Electroencephalography and Clinical Neurophysiology, 59, 477-488.

McCarthy, G., \& Wood, C. C. (1984). Intracranially recorded event-related potentials during sentence processing. Society for Neuroscience Abstracts, 10, 847.

Monsell, S. (1985). Repetition and the lexicon. In A. W. Ellis (Ed.), Progress in the psychology of language (Vol. 2 pp. 147-195). Hillsdale, NJ: Lawrence Erlbaum.

Monsell, S. (1991) The nature and locus of word frequency effects in reading. In D. Besner \& G. W. Humphreys (Eds.), Basic processes in reading: Visual word recognition (pp. 148-197). Hillsdale, NJ: Lawrence Erlbaum.

Morton, J. (1969). Interaction of information in word recognition. Psycbological Review, 76, 165-178.

Nagy, M. E., \& Rugg, M. D. (1989). Modulation of ERP by word repetition: The effects of inter-item lag. Psycbophysiology, 26, 431-436.

Neville, H. J., Kutas, M., Chesney, G., \& Schmidt, A. (1986). Event-related brain potentials during the initial encoding and subsequent recognition memory of congruous and incongruous words. Journal of Memory and Language, 25, 75-92.

Paller, K. A. (1990). Recall and stem-completion priming have different electrophysiological correlates are modified differentially by directed forgetting. Journal of Experimental Psycbology: Learning, Memory, and Cognition, 16, 10211032.

Paller, K. A., Kutas, M., \& Mayes, A. (1987). Neural correlates of encoding in an incidental learning paradigm. Electroencephalography and Clinical Neurophysiology, 67, 360-371.

Paller, K. A., Kutas, M., Shimamura, A. P., \& Squire, L. R. (1987). Brain responses to concrete and abstract words re- flect processes that correlate with later performance on tests of recall and stem-completion priming. In R. Johnson, Jr., J. Rohrbaugh, \& R. Parasuraman (Eds.), Current research in event-related brain potentials, electroencephalography and clinical neurophysiology, Supplement 40 (pp. 360365). Amsterdam: Elsevier.

Paller, K. A., McCarthy, G., \& Wood, C. C. (1988). Brain potentials predictive of later performance on tests of recall and recognition performance. Biological Psychology, 26, 269276.

Paul, D. D., \& Sutton, S. (1972). Evoked potential correlates of response criterion in auditory signal detection. Science, $177,362-374$

Pineda, J. A., Foote, S. L., \& Neville, H. J. (1989). Effects of locus coeruleus lesions on auditory, long latency, event- related potentials in monkey. The Journal of Neuroscience, 9 , 81-93.

Roediger, H. L., III, Weldon, M. S., \& Challis, B. H. (1989) Explaining dissociations between implicit and explicit measures of retention: A processing account. In $\mathrm{H}$. L. Roediger, III and F. I. M. Craik (Eds.), Varieties of memory and consciousness, essays in bonour of Endel Tulving (pp. 3-42). Hillsdale, NJ: Lawrence Erlbaum.

Rugg, M. D. (1983). Further study of the electrophysiological correlates of lexical decision. Brain and Language, 19, 142- 152.

Rugg, M. D. (1984). Event-related potentials in phonological matching tasks. Brain and Language, 23, 225-240.

Rugg, M. D. (1985). The effects of semantic priming and word repetition on event-related potentials. Psychophysiology, 22, 642-647.

Rugg, M. D. (1987). Dissociation of semantic priming, word and non-word repetition effects by event-related potentials. Quarterly Journal of Experimental Psychology, 39A, 123148.

Rugg, M. D. (1990) Event-related brain potentials dissociate repetition effects of high- and low-frequency words. Memory \& Cognition, 18, 367-379.

Rugg, M. D., Furda, J., \& Lorist, M. (1988). The effects of task on the modulation of event-related potentials by word repetition. Psychophysiology, 25, 55-63.

Rugg, M. D., \& Nagy, M. E. (1987). Lexical contribution to non-word repetition effects: Evidence from event-related potentials. Memory \& Cognition, 15, 473-481.

Rugg, M. D., \& Nagy, M. E. (1989). Event-related potentials and recognition memory for words. Electroencepalography and Clinical Neurophysiology, 72, 395-406.

Sanquist, T. F., Rohrbaugh, J. W., Syndulko, K., \& Lindsley, D. B. (1980). Electrocortical signs of levels of processing: Perceptual analysis and recognition memory. Psychopbysiology, $17,568-576$

Scarborough, D. L., Cortese, C., \& Scarborough, H. S. (1977). Frequency and repetition effects in lexical memory. Jour nal of Experimental Psychology: Human Perception and Performance, 3, 1-17.

Schacter, D. L. (1987). Implicit memory: History and current status. Journal of Experimental Psychology: Learning, Memory, and Cognition, 13, 501-518.

Schreuder, R., \& Flores d'Arcais, G. B. (1989). Psycholinguistic issues in the lexical representation of meaning. In W. Marslen Wilson (Ed.), Lexical representation and process (pp. 409-436). Cambridge: MIT Press.

Smith, M. E., \& Halgren, E. (1987). Event-related potentials during lexical decision: Effects of repetition, word frequency, pronounceability, and concreteness. In R. Johnson, Jr., J. W. Rohrbaugh, \& R. Parasuraman (Eds.), Current trends in event-related potential research. Electroencephal. 
ography and Clinical Neurophysiology, Supplement 40 (pp. 417-421). Amsterdam: Elsevier.

Smith, M. E., \& Halgren, E. (1989). Dissociation of recognition memory components following temporal lobe lesions. Journal of Experimental Psychology: Learning, Memory, and Cognition, 15, 50-60.

Smith, M. E., Stapleton, J. M., \& Halgren, E. (1986). Human medial temporal lobe potentials evoked in memory and language tasks. Electroencephalography and Clinical Neurophysiology, 63, 145- 149 .

Squires, K. C., Hillyard, S. A., \& Lindsay, P. H. (1973a). Cortical potentials evoked by confirming and disconfirming feedback during an auditory discrimination. Perception and Psycbophysics, 13, 25-31.

Squires, K. C., Hillyard, S. A, \& Lindsay, P. H. (1973b). Vertex potentials evoked during auditory signal detection: Relation to decision criteria. Perception and Psychophysics, 14, 265272.

Squires, K. C., Squires, N. K., \& Hillyard, S. A. (1975). Decision- related cortical potentials during an auditory signal detection task with cued observation intervals. Joumal of Experimental Psychology: Human Perception and Performance, 104, 268-279.

Tulving, E., Schacter, D. L., \& Stark, H. A. (1982). Priming effects in word-fragment completion are independent of recognition memory. Joumal of Experimental Psychology: Learning, Memory, and Cognition, 8, 336-342.

Van Petten, C. (1989). Context effects in word recognition:
Studies using event-related brain potentials. Doctoral dissertation, University of California, San Diego.

Van Petten, C., \& Kutas, M. (1988). The use of event-related potentials in the study of brain asymmetries. International Journal of Neuroscience, 39, 91-99.

Van Petten, C., \& Kutas, M. (1990). Interactions between sentence context and word frequency in event-related brain potentials. Memory and Cognition, 18, 380-393.

Van Petten, C., \& Kutas, M. (1991a). Influences of semantic and syntactic context on open and closed class words. Memory and Cognition, 19, 95-112. In press.

Van Petten, C., \& Kutas, M. (1991b). Electrophysiological evi. dence for the flexibility of lexical processing. In G. Simpson (Ed.), Word and sentence (pp. 129-174). Amsterdam: North Holland Press.

Vasey, W. V., \& Thayer, J. F. (1987), The continuing problem of false positives in repeated measures ANOVA in psychophysiology: A multivariate solution. Psychophysiology, 24, 479-486.

Verleger, R. (1988). Event-related potentials and cognition: A critique of the context updating hypothesis and an alternative interpretation of the P3. Behavioral and Brain Sciences, 11, 343-356.

Warrington, E. K., \& Weiskrantz, L. (1974). The effect of prior learning on subsequent retention in amnesic patients. Neuropsychologia, 12, 419-428.

Zipf, G. K. (1945). The meaning-frequency relationship of words. Journal of General Psychology, 33, 251-256. 